\title{
MNIGLASSIFIED
}

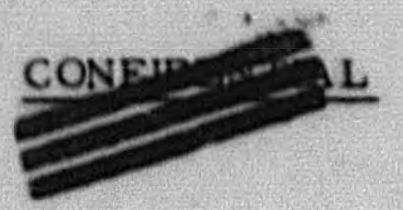

Contuact No. W-7405-eng -92
Report No, BMI-1040

Metallurgy and Ceramics

(M-3679, 16th Ed.)

\section{PLASTIC DEFORMATION IN GROOVED ROLLS}

by

Henry A. Saller

John R. Keeler *

Lee J. Cuddy

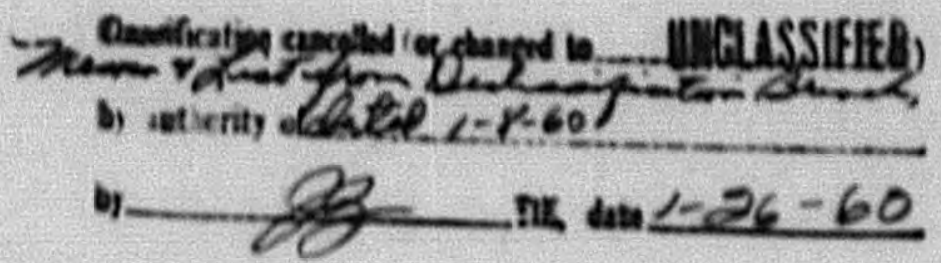

September 27, 1955

\section{RESTRICTED DATA}

This document conting

Energy Act of 18Sy

In a defined in the Atomic

is any mannet to sital or disclowe of is costens thorized perkon is probibited.

BATTELLE MEMORIAL INSTITUTE $505 \mathrm{King}$ Avenue

Columbus 1, Ohio

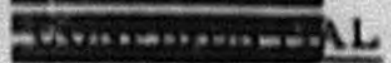




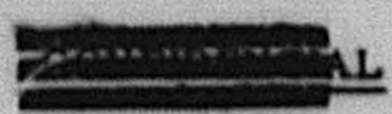

5 and 6

\section{TABLE OF CONTENTS}

Page

ABSTRACT ..................... 7

INTRODUCTION ........................ 7

PRELIMINARY ROLLING STUDIES ................ 8

Preparation of Composite Uranium Ingots . . . . . . . . 8

Preparation of Composite Plasticine Ingots .......... 10

Effect of Rolling Variables on Plasticine Deformation . . . . 12

Comparison of Deformation in Uranium and Plasticine . . . . 19

Plasticine Flow PATtERNS. . . . . . . . . . . . . 23

FMPC Breakdown Rolls. . . . . . . . . . . . 23

FMPC Finishing Grooves... ............. 26

Diamond Grooves. . . . . . . . . . . . . . . . 29

Hand-Rounding Grooves................. 29

CORRELATION OF PHYSICAL PROPERTIES OF URANIUM AND

PlastiC Flow . . . . . . . . . . . . . . 36

X-Ray Diffraction Studies . . . . . . . . . . . . 36

Thermal-Expansion Measurements .... . . . . . . . 43

Ultrasonic-Transmission Properties ............. 43

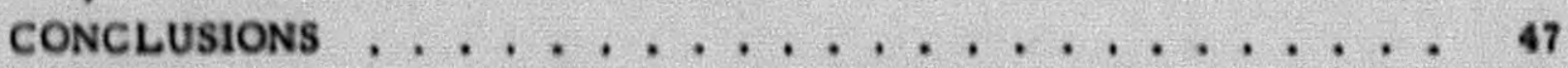

REFERENCES, ., ., , ., , , ., ., , , 50 


\title{
UNGLASSIFIED
}

\section{PLASTIC DEFORMATION IN GROOVED ROLLS}

\author{
Henry A. Saller, John R. Keeler, and Lee J. Cuddy
}

The direction and extent of lateral deformation during the rolling of rod in grooved rolls was investigated. Composite wanian ingots and laminated ingots of coiored modeling clay uere used to intestigate the deformation in diamond, oval-round, handeround, and the FMPC beabdown rolls.

X-ray diffraction studies for preferred orientation neere made on small areas of the crosa section of wranium rod rolled in the standard FUPC schedule and on sections of rod rolled in diamond grooves. A tendency for the (002) planes to align parallel to the direction of lateral flou nas observed in sectiens near the sufface of the nod. At the center of the rod, no correlation was found between the direction of flow and the orientation.

The coefficients of thermal expansion in tho radial directions in a diamond-rolled tod wete the same, although marked differences in the direction of lateral flow in these areas had bepn observed.

\section{INTRODUCTION}

A study of the deformation characteristics of uranium in grooved rolls was undertaken for the National Lead Company. This study was to provide a basis for possible improvements in the uniformity of the rolled rod produced for the Hanford and Savannah River reactors.

At present, uranium ingots are rolled in a $20-\mathrm{in}$, roughing mill, using typical steel-mill practice of bullhead-edger passes with a final oval reduction. After reheating, the oval billet is finish-rolled in a six-stand continuous finishing mill in alternate oval-round grooves.

Although the rolling characteristics in these rolls are good and the resulting rod has good surface quality, some evidence of inhomogeneity in the rod has been observed by some techniques. In the as-rolled rod, the radial transmission for ultrasonic energy varies around the circumference and shows a maxima on two diameters roughly 90 deg apart. Although beta quenching generally eliminates this phenomenon, a tendency to split at the original maxima persists during subsequent thermal stress cycling. 
The present investigation was undertaken to determine the manner in which plastic deformation occurs in the FMPC rolls and in other roll shapes and to attempt to correlate the deformation characteristics with the crystallographic and physical properties of the rolled rod.

In order to reduce the cost of rolls and facilitate the investigation, a modeling clay, Plasticine, which is available in various colors, was used as a stand-in for metallic uranium. This material, has been used in earlier studies of plastic deformation with considerable success $(1,2,3,4) *$, and initial tests comparing its deformation with that of uranium indicated a close correlation in the plastic-deformation characteristics.

The deformation of Plasticine in the various types of gropved rolls used to produce a round rod was investigated. Subsequently, an effort was made to correlate the observed flow characteristics with $\mathrm{X}$-ray diffraction data obtained on similarly rolled uranium rod.

\section{PRELIMINARY ROLLING STUDIES}

Any study of the plastic deformation during rolling is complicated by the necessity for devising methods of detecting and measuring the direction and amount of deformation in the metal without interfering with the flow. Experimental studies with grooved rolls are further complicated by the variety of groove shapes possible, and the high cost of rolls. Therefore, the use of a plastic clay was considered so that low-cost wooden rolls could be used.

Preliminary studies were made to determine whether the flow of such a clay in grooved rolls would correlate with the flow of uranium in similarly shaped grooves.

\section{Preparation of Composite Uranium Ingots}

Two types of composite uranium ingots were prepared for this study. The most successful of these was an ingot which contained longitudinal incerts. Five holes, 3 in, deep by $3 / 16$ in, in diameter were drilled parallel to the axis of a 1-7/16-in, -diameter ingot at the positions shown in Figure 1 . Pins were machined from swaged uranium rod to fit into each of the holes, the pins were held in place by a weld at the end. Prior to rolling, the composites were beta heat treated to homogenize the structure. After rolling,

QReferences at end, 


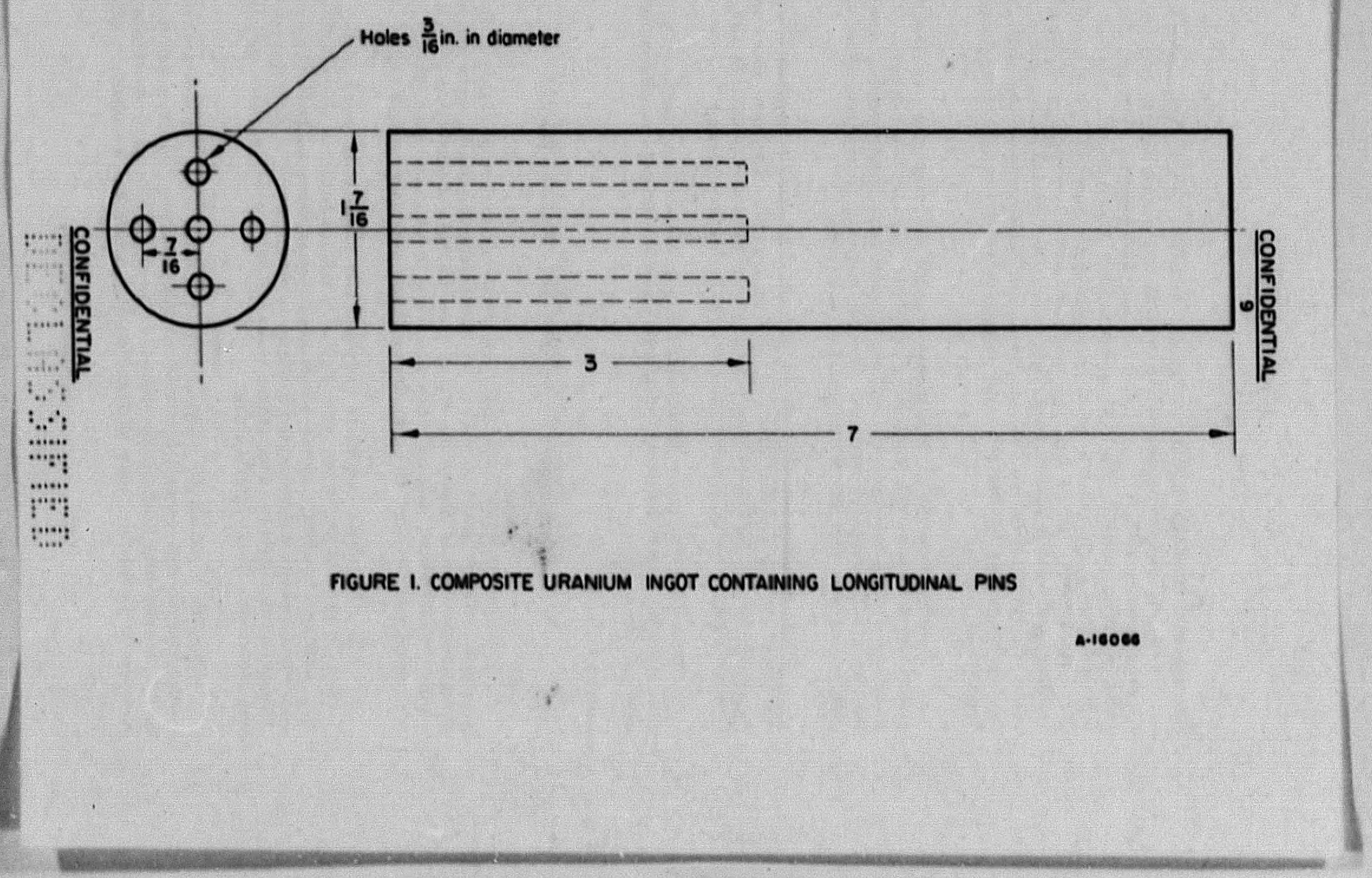




\section{CONFEENTLAL}

10

the shape of the insert gave an indication of the deformation which had occurred. In preparing the other type of composite ingot, two zirconium wire grids with $1 / 2-$ in. spacing were cemented into a cylindrical graphite mold perpendicular to the axis of the mold. Uranium was bottom peured into the mold to produce a solid ingot having zirconium $\mathrm{g}$ rids at intervals along the length. After rolling, the rods were sectioned and the deformation of the grids determined radiographically. As indicated in subsequent sections, evidence of gross deformation could be observed with the grid-type composite ingot, but the pin-type ingots were much easier to prepare and examine.

In addition to using composite inguts, an attempt was made to show the direction of flow by macroetching partially rolled uranium ingots. Sections were cut from uranium rods rolled through different grooves, and etched electrolytically in a 15 per cent phosphoric acid solution at a current density of 0.5 amp per $\mathrm{cm}^{2}$ for a period of 5 to $10 \mathrm{~min}$.

Some evidence of flow could be observed during the initial stages of reduction before recrystallization had occurred. The flow lines were not clear, however, and this method was not considered a satisfactory means of determining the direction or extent of local deformation.

Efforts to utilize a grain-boundary precipitate to outline the grains and thus provide a grid work which would show the effects of deformation were also unsuccessful.

\section{Preparation of Composite Plasticine Ingots}

Composite Plasticine ingots were used for comparison with the uranium. These were prepared by cementing together, with benzene, alternate sheets of blue and white Plasticine which had previously been rolled to uniform thickness. Ingots were cut from these laminated blocks to the sizes and shapes necessary to enter the various sets of grooved rolls.

The composite ingots of uranium and Plasticine were rolled through similarly shaped grooves, and the local deformation in the cross section of the rods determined. A few Plasticine ingots were rolled in the steel rolling mill, but the handling and guiding problem made it difficult and unsafe. Therefore most of the Plasticine was rolled in wooden rolls similar, but not identical, to the steel rolls.

Figure 2 shows the shape of the grooves cut in the wooden golls. These include the complete FMPC breakdown and finishing grooves for Hanford rod, and diamond breakdown grooves, and hand-rounding grooves similar in design to those at Simonds Saw and Steel Company. All of the se 

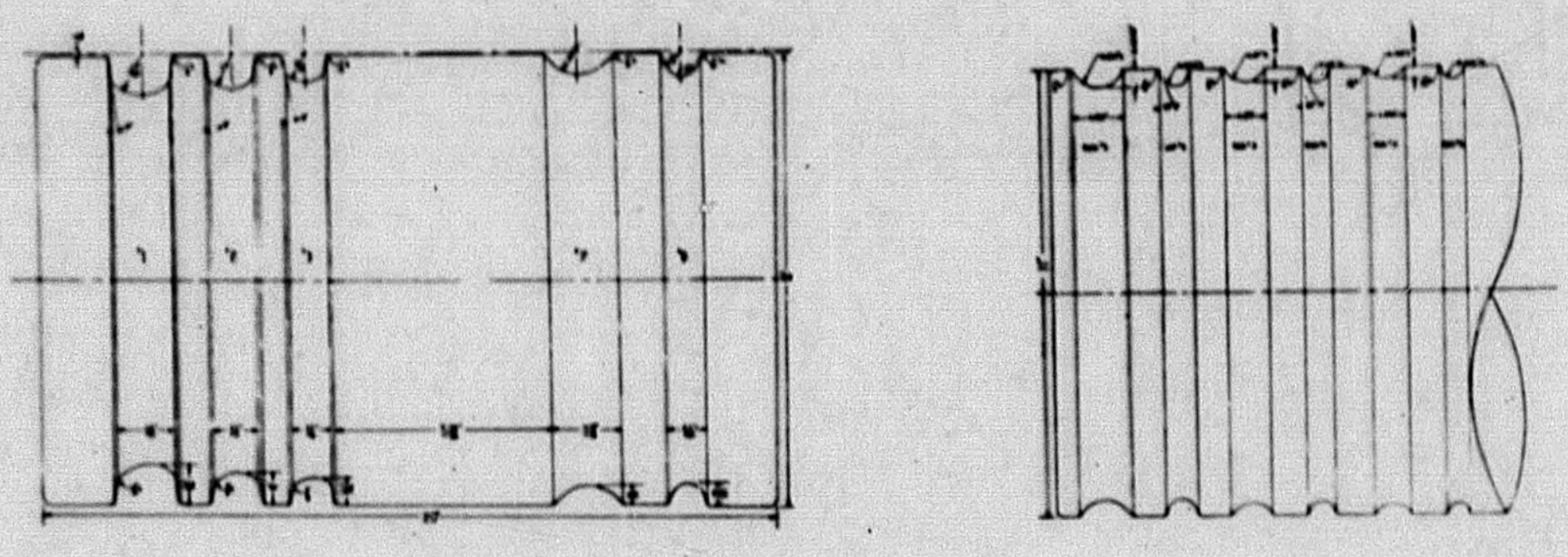

……|

N22306

Roll W-1, Model of FMPC Roughing Rolls

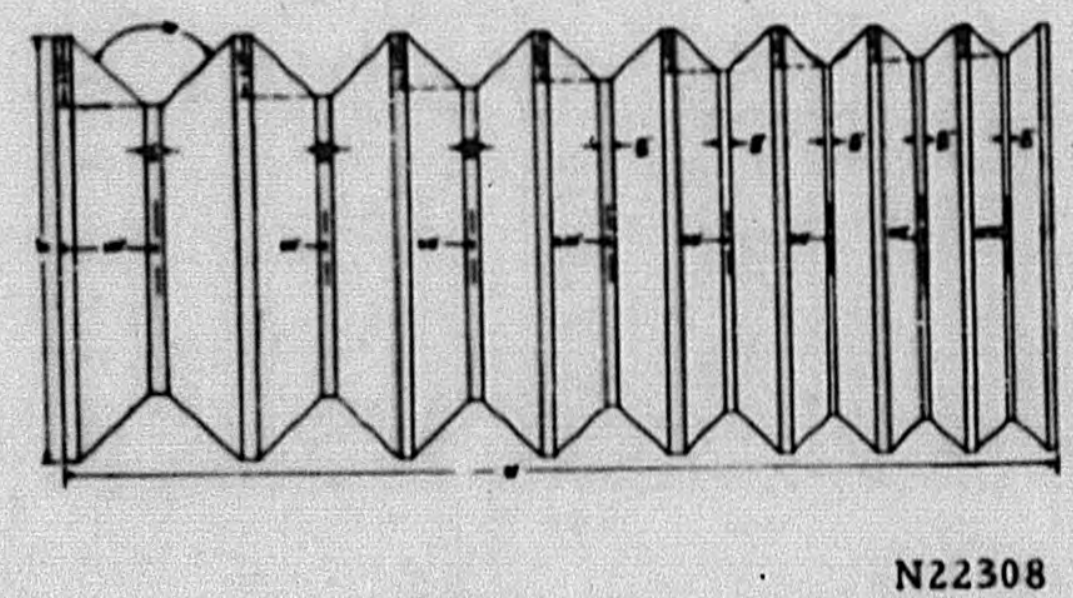

Roll w-2, Model of Simonds Roughing Rolls

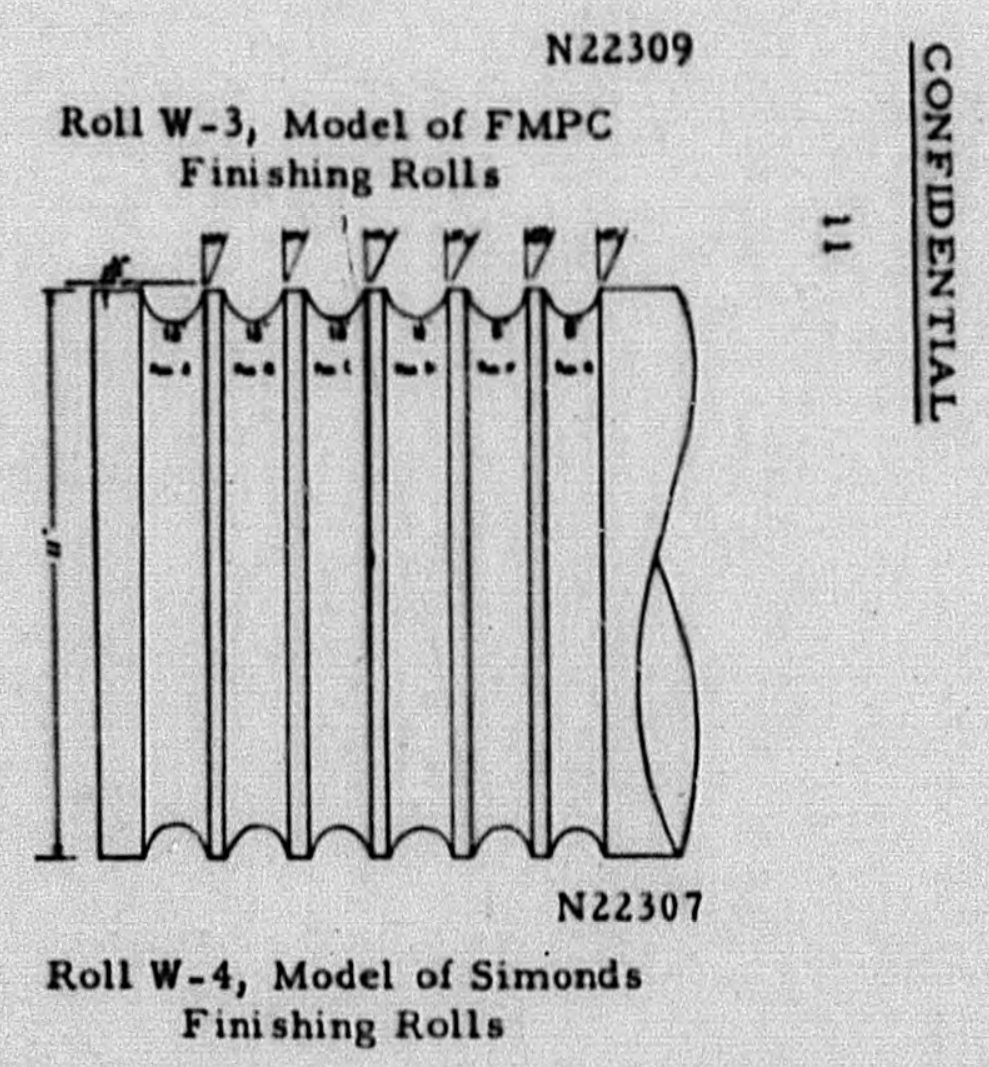

FIGURE 2. FOUR SETS OF WOODEN ROLLS USED TO ROLL PLASTICINE 


\section{CONFIDENTIAL}

grooves are one-half scale models of the respective rolls used for uranium production.

The composite uranium billets were rolled in the Battelle 8 by 12 -in. and 5 by $8-i n$, experimental mills. Figure 3 shows the design of the rolls available for these mills.

\section{Effect of Rolling Variables on Plasticine Deformation}

Prior to rolling the Plasticine ingots for comparison with uranium, several exploratory tests were made to determine the effect of lubrication, rate of reduction, and hardness or plasticity on the rolling characteristics of the Plasticine.

Of these rolling variables, lubrication had the most significant effect on the flow characteristics. Two sets of similar Plasticine ingots were prepared and rolled, using the schedule shown in Table 1. One set was rolled dry with only a light dusting of talcum powder to prevent sticking. The other set was lubricated before each pass with Polyethylene 600 , a water-soluble organic compound of high lubricity. Figures 4 through 7 show the flow patterns observed at various stages in the reduction.

TABLE I. ROLLING SCHEDULE FOR PLASTICINE INGOTS ROLLED ON MODEL FMPC BREAKDOWN ROLLS

\begin{tabular}{|c|c|c|c|}
\hline Pass & & Groove & $\begin{array}{l}\text { Roll Parting. } \\
\text { in. }\end{array}$ \\
\hline 1 & & Bullhead & $2 \cdot 1 / 8$ \\
\hline 2 & & Bullhead & $1-15 / 16$ \\
\hline 3 & & Bullhead & $1 \cdot 11 / 16$ \\
\hline 4 & & Bullhead & $1-9 / 16$ \\
\hline 5 & & No. 1 - Edget & $5 / 8$ \\
\hline 6 & & No. I - Edger & $7 / 16$ \\
\hline $7(a)$ & & No. 1 - Edger & $11 / 32$ \\
\hline 8 & & No. 1 - Edger & $1 / 4$ \\
\hline 9 & 1 & Bullhead & $1-1 / 4$ \\
\hline 10 (a) & 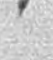 & No. 2 - Edger & $11 / 16$ \\
\hline $11^{(a)}$ & & No. 2 - Edget & $3 / 8$ \\
\hline 12 & & No. 2 - Edger & $1 / 4$ \\
\hline 13 & & Bullhead & $1-1 / 8$ \\
\hline $14^{(6)}$ & & No. 3 - Edger & $3 / 8$ \\
\hline $15^{(a)}$ & & No. 3 - Edger & $5 / 16$ \\
\hline 16 & & No. 3 - Edger & $1 / 4$ \\
\hline 17 & & No. ?- Oval & $1 / 8$ \\
\hline $18^{(a)}$ & & No. 9 - Preoval & $1 / 4$ \\
\hline 19 & & No. 9 - Preoval & $1 / 8$ \\
\hline
\end{tabular}

(a) Pass added to FMPC schedule to reduce overfilling. 


\section{CONFIDENTIAL}

13

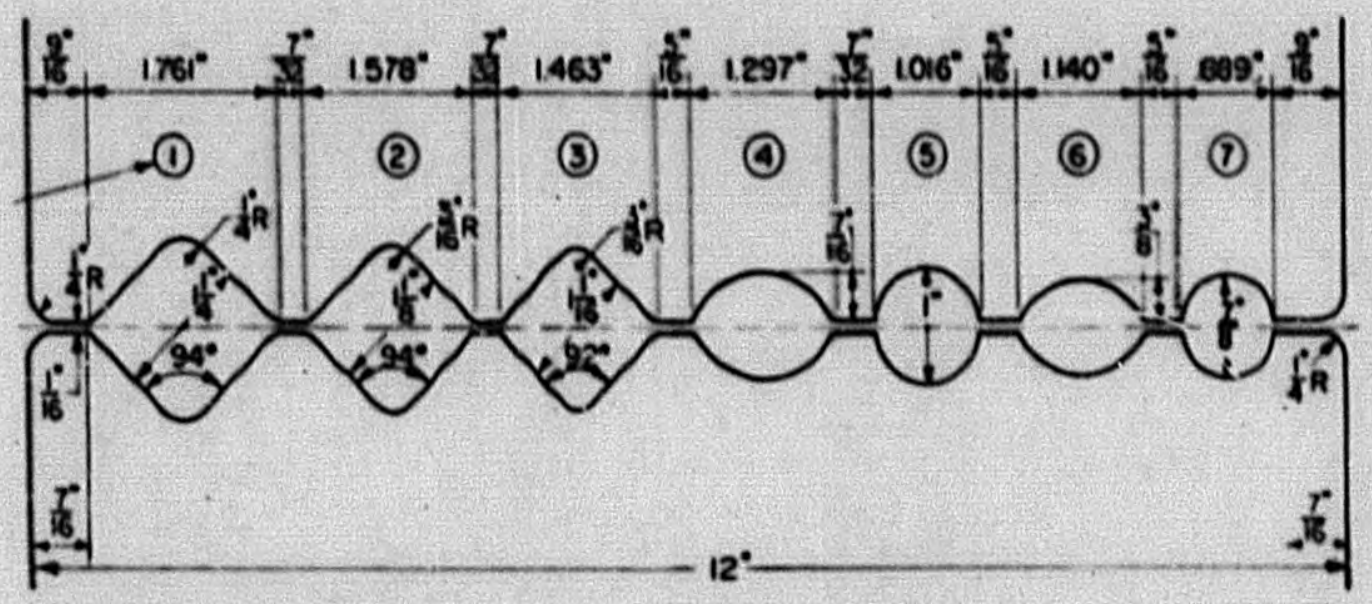

Roll S-1, 8-In, Mill, Diamond-Oval-Round Grooves

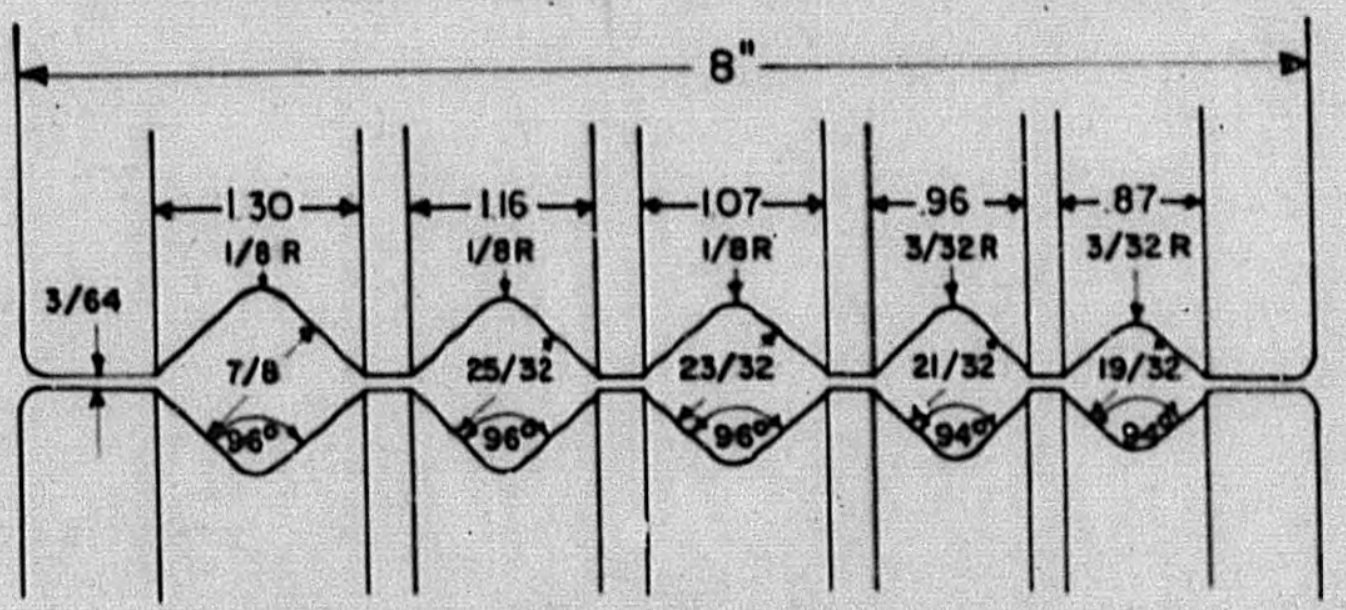

Roll S-3, 5-In, Mill, Diamond Grooves

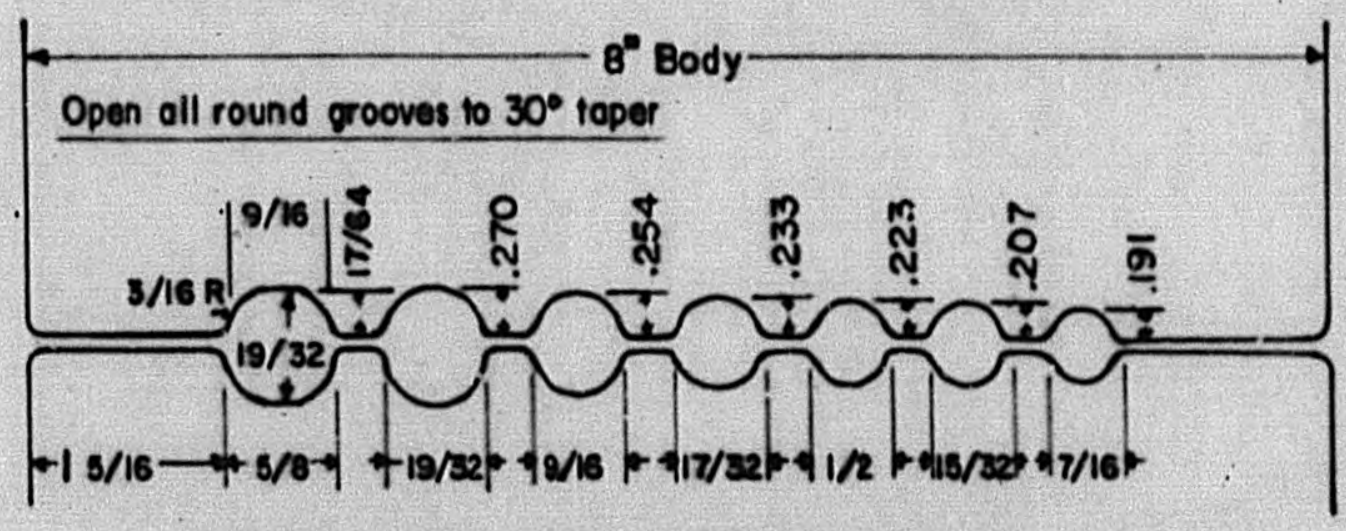

Roll S-4, 5-In. Mill, Hand-Rounding Grooves

N22018

FIGURE 3. THREE SETS OF GROOVED STEEL ROLLS USED TO ROLL URANIUM ROD 


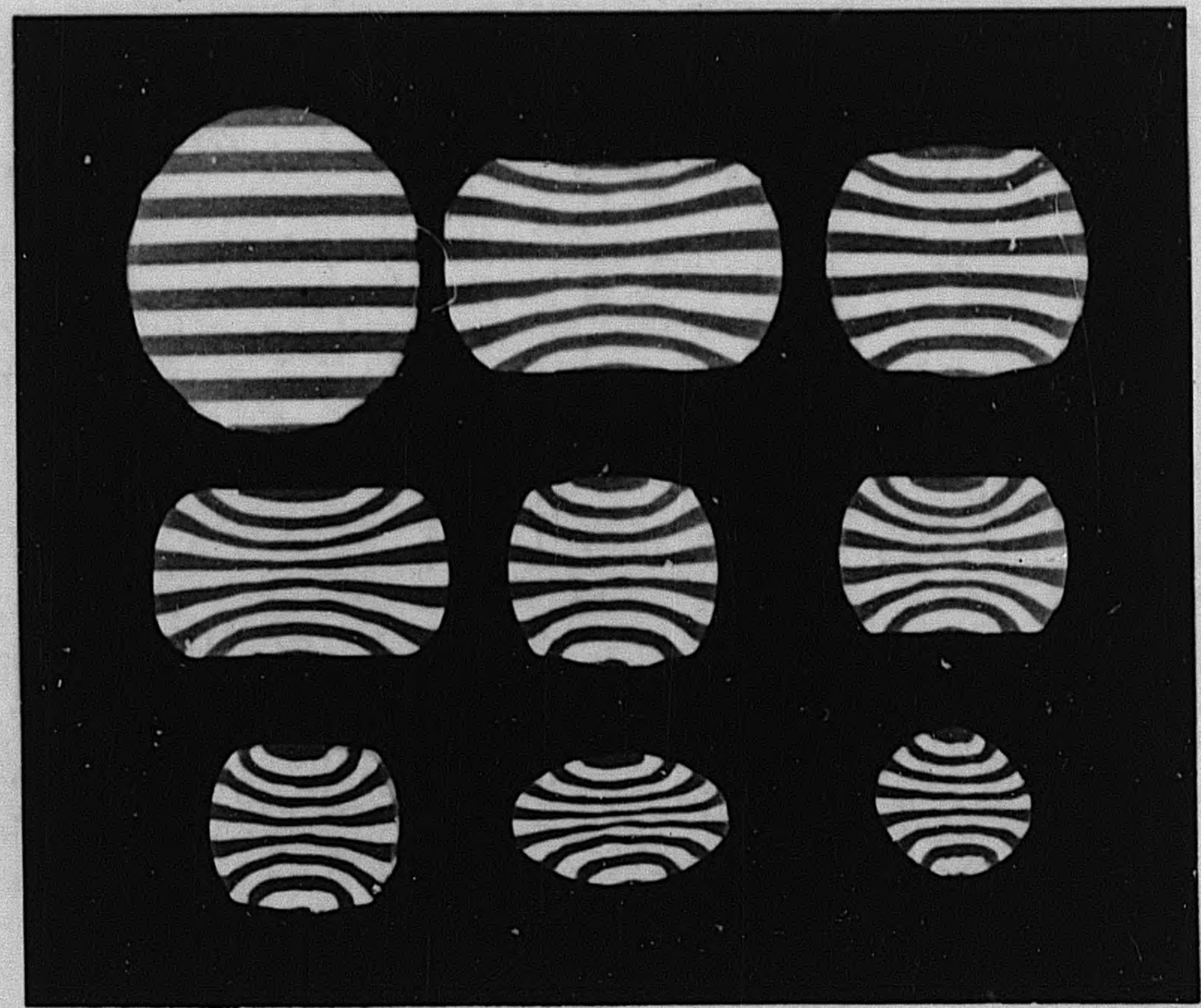

FIGURE 4. SECTIONS OF UNLUBRICATED PLASTICINE INGOT AND ROD AFTER ROLLING THROUGH PASSES $4,8,9,12,13,16,17$, AND 19 IN THE MODEL FMPC ROUGHING ROLLS 


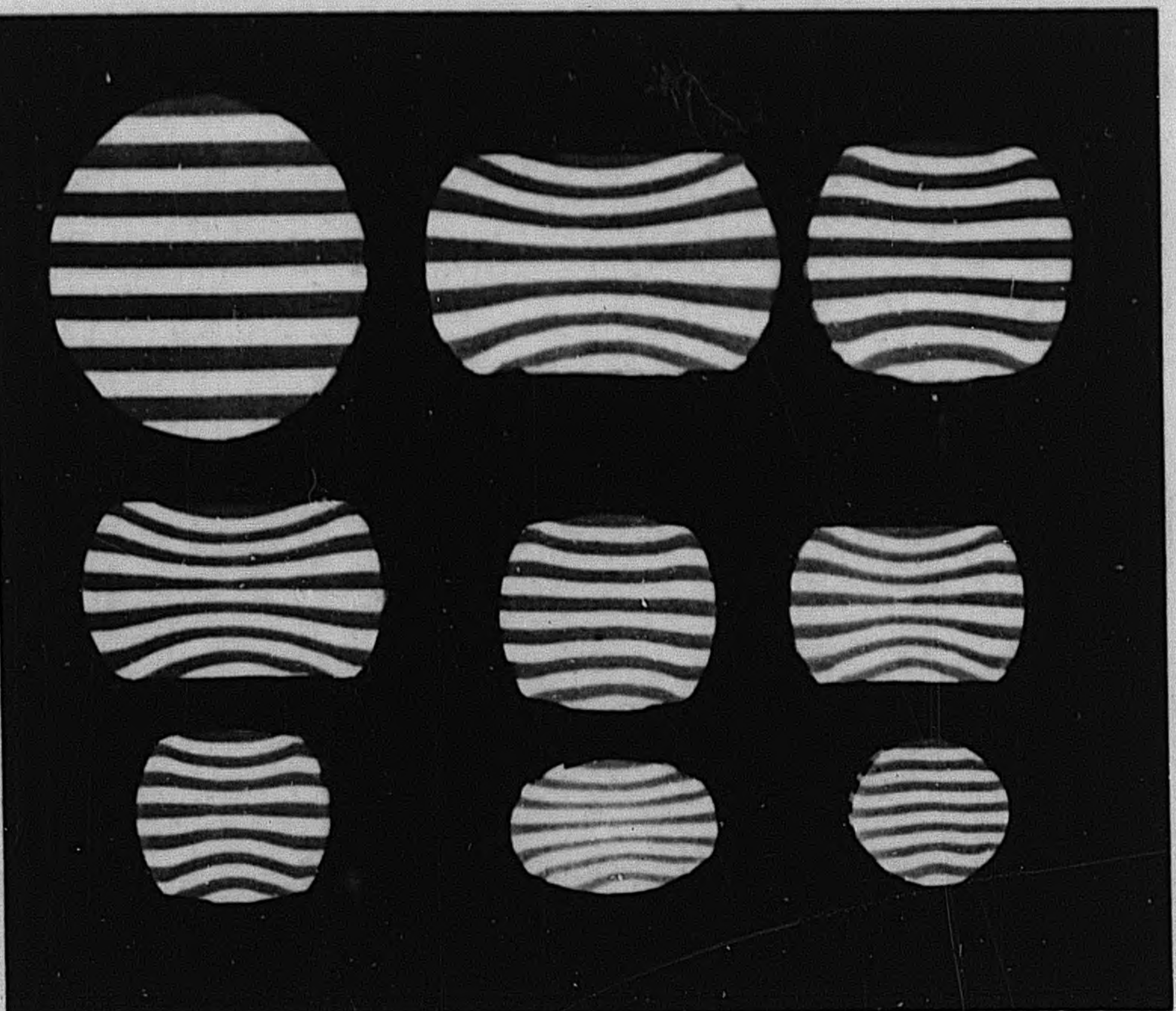
PASSES 4, 8, 9, 12, 13, 16, 17, AND 19 IN THE MODEL FMPC ROUGHING MILL 


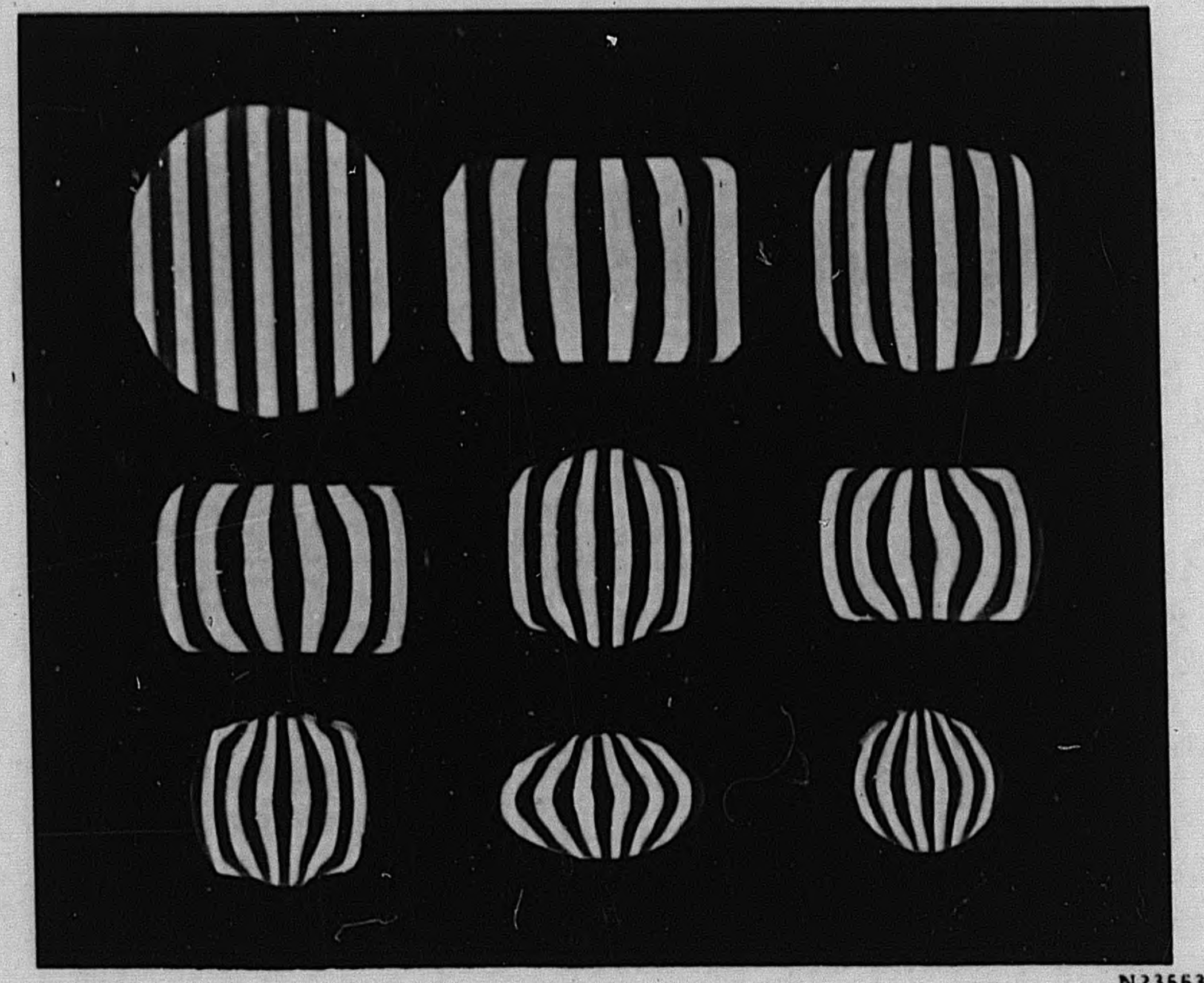

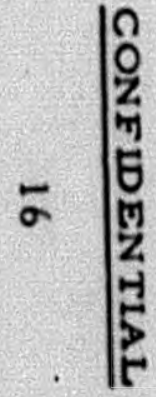

N23553

FIGURE 6. SECTIONS OF UNLUBRICATED PLASTICINE INGOT AND ROD AFTER ROLLING THROUGH PASSES $4,8,9,12,13,16,17$, AND 19 IN THE MODEL FMPC ROUGHING ROLLS 

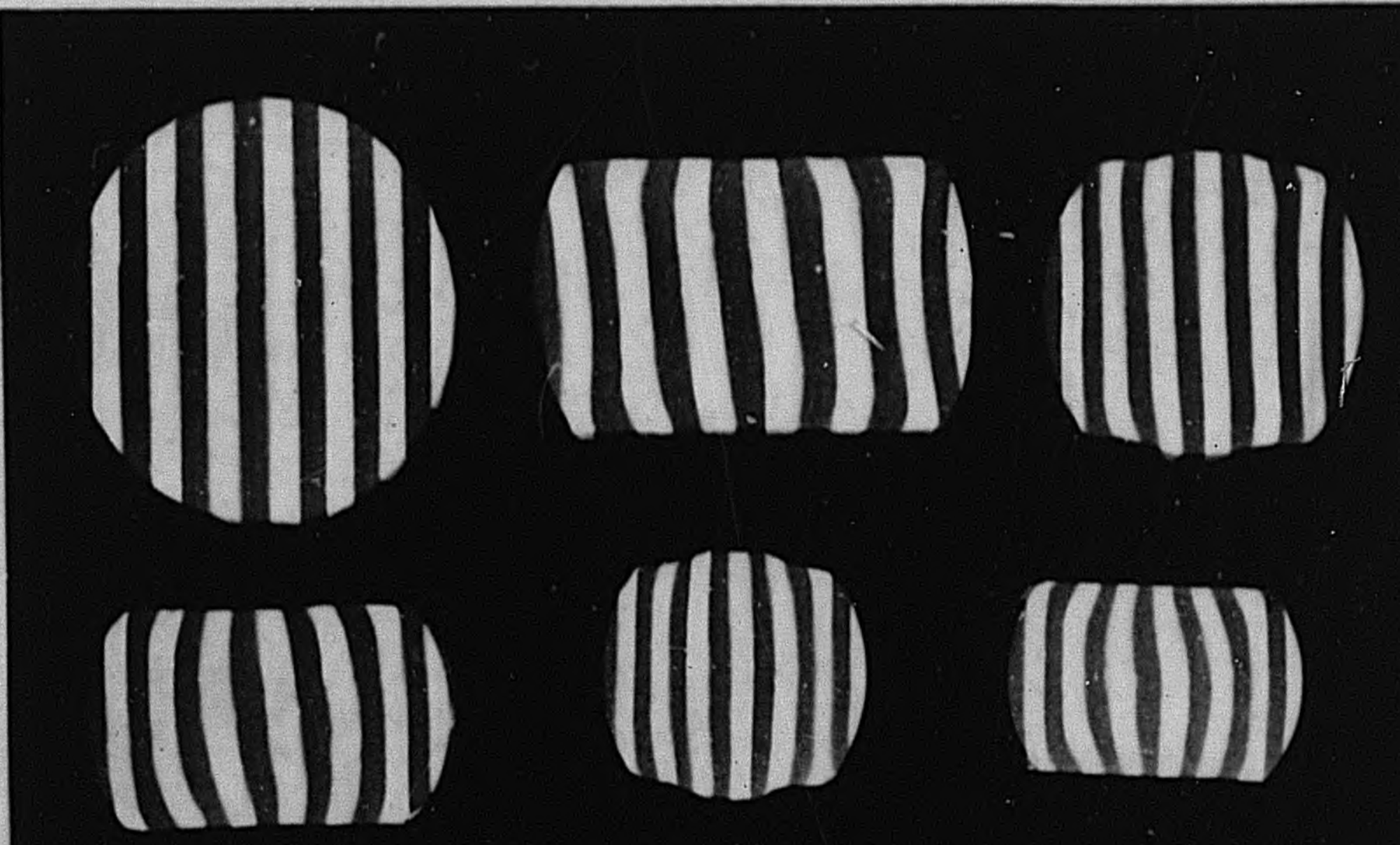

$=$

:

:.....
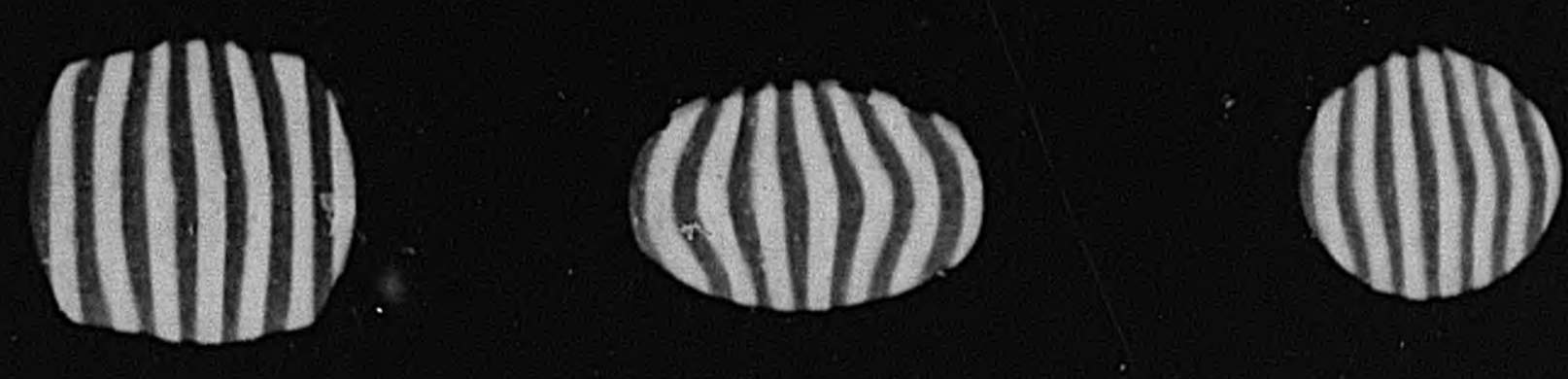

FIGURE 7. SECTIONS OF UURRCATED PLASTICENE DNCOT AND POD AFTER DOUING THPOUGH PASSES 4, MODEL FMPC ROUGHING MaLL 


\section{CONFIDENTIAL}

The shapes of the lamina indicate that lubrication increased the uniformity of deformation. Both horizontal and vertical lamina had a greater tendency to remain straight and parallel during the reduction. This is particularly evident in the sections of the finished billet. Lubrication al so reduced the horizontal spread in the rolls and decreased the amount of finning observed,

The effect of plasticity of the clay was investigated by rolling several ingots which had been prepared from Plasticine containing added amounts of talcum powder. The addition of the talcum powder increased the hardness and decreased the plasticity of the standard grade of material. The hardened clay was quite short and broke under a tensile load with less elongation than the as-received clay.

The "hard" ingots were rolled in the FMPC breakdown rolls and the deformation pattern of the lamina compared with that of similarly rolled standard Plasticine ingots. The marked difference in plasticity had little effect on the deformation patterns observed. The horizontal spread of the ingot in the rolls was greater with this harder material, and this resulted in a tendency to overfill the grooves and produce fins, however, the shape of the larnina in both cases was essentially the same after the final pass.

Increasing the draft or rate of reduction to that shown in Table 2 increased the amount of horizontal spread when roling the standard asreceived Plasticine. This was particularly evident in the edger passes when the increased spread resulted in overfilling and slight finning. However, the over-all effect on the direction and amount of lateral flow as indicated by the shape of the lamina was not great.

TABLE 2. ROLLING SCHEDIILE FOR RAPID REDUCTION OF PLA STICINE INGOTS ON MODEL. FMPC BREAKDOWN ROLLS

\begin{tabular}{|c|c|c|}
\hline Pan & Grovve & $\begin{array}{c}\text { Roll Parting. } \\
\text { in. }\end{array}$ \\
\hline 1 & Bullhead & 2 \\
\hline 2 & Bulliead & $1-9 / 16$ \\
\hline 3 & No. 1. Edger & $1 / 4$ \\
\hline 4 & Bullhead & $1-1 / 4$ \\
\hline 5 & No. 2 - Edger & $1 / 4$ \\
\hline 6 & Bulthead & $1-1 / 8$ \\
\hline 1 & No., 3 - Edger. & $1 / 4$ \\
\hline 8 & No. 7 - Oval & $1 / 8$ \\
\hline 8 & No. 9 - Preoval & $1 / 8$ \\
\hline
\end{tabular}

On the basis of the above results it was concluded that small variations in plasticity from lot to lot of the Plasticine would not significantly affect the deformation characteristics of the material. Similarly, considerable 


\section{CONELENTLAL}

19

latitude was possible in the rolling schedule without appreciable changes in the flow patterns observed. In all of the subsequent rolling, however, a lubricant was used.

\section{Comparison of Deformation in Uranium and Plasticine}

Following the above preliminary studies with Plasticine, the lateral deformation of uranium and Plasticine was compared for the following groove shapes; bullhead or flat reduction of an initially round ingot, diamond, diamond plus hand rounds and finally diamond-oval-rounds.

The composite uranium ingots, $1 . .7 / 16$ in, in diameter and containing longitudinal pins, were rolled as shown in Table 3 . The samples were heated to $1175 \mathrm{~F}$ in a carbonate salt bath and reheated after every third or fourth pass as required.

The Plasticine ingots were rolled in similarly shaped wooden rolls to the same over-all reductions.

After rolling, the rods of both materials were sectioned and the deformation of the various inserts measured. In both uranium and Plasticine, the ratio, $\frac{H}{W}$, of the final width, $W$, and height, $H$, of the inserts was taken as a measure of the lateral deformation. For pins which were not located on the horizontal or vertical axes of the cross section, a radius was drawn from the center of the rod through the center of the insert. The maximum dimensions of the insert were then measured in the radial direction and also perpendicular to the radius. The ratio of these dimensions was taken as the induction of the amount of deformation. Thus in the diamond rod, the inserts on the diagonals of the dianiond were on the vertical and horizontal axes but inserts at the flat sides of the rod were on radii drawn from the center of the rod.

A summary of the rolling conditions and deformation is shown in Table 3. The appearance of the cross sections is shown in Figures 8 and 9.

In order to measure the deformation in the Plasticine, two ingots were rolled, one with the lamina vertical and one with the lamina horizontal. Each of these was photographed after sectioning and the negatives superimposed. A print was then made which was a composite and showed the change in shape of initially square segments.

The direction of flow in both material s appears to be quite similar. This is particularly evident in the diamond grooves where the inserts at the conners of the diamond tend to elongate on the diagonal axes and inserts at the flat faces elongated parallel to that face. 
TABLE 3. COMPARISON OF DEFORMATION IN URANIUM AND PLASTICINE INGOTS AFTER ROLLING IN SHAPED GROOVES

\begin{tabular}{|c|c|c|c|c|c|c|c|c|c|c|}
\hline \multirow[b]{2}{*}{$\begin{array}{l}\text { Ingot } \\
\text { Material }\end{array}$} & \multirow{2}{*}{$\begin{array}{c}\text { Diametet } \\
\text { of Ingot. } \\
\text { In. }\end{array}$} & \multicolumn{4}{|c|}{ Description of Rolls } & \multirow{2}{*}{$\begin{array}{l}\text { Reduction } \\
\text { in Area, } \\
\text { pet cent }\end{array}$} & \multicolumn{4}{|c|}{ Deformation (Ratio $\frac{\mathrm{H}}{\mathrm{W}}$ of Segments) } \\
\hline & & Shape & Rolls (a) & Material & $\begin{array}{c}\text { Dlameter, } \\
\text { in. }\end{array}$ & & Center & $\begin{array}{c}\text { Vertical } \\
\text { Axis }\end{array}$ & $\begin{array}{c}\text { Hotizontal } \\
\text { Axis }\end{array}$ & $\begin{array}{r}\text { Diagonal } \\
\text { Axis (b) }\end{array}$ \\
\hline Uranium & $1.7 / 16$ & Fat & - & Steel & 8 & $37.5(\mathrm{c})$ & 0.47 & 0.52 & 0.80 & - \\
\hline Planticine & $2 \cdot 1 / 2$ & Flat & - & Wood & 11 & $35.5^{(d)}$ & 0.45 & 0.47 & 0.82 & - \\
\hline \multirow[t]{2}{*}{ Uranium } & $1.7 / 16$ & Diamond & $s-1$ (e) & Steel & 8 & & & & & \\
\hline & & & s-3 & Steel & 5 & 80 (total) & 1.20 & 1,14 & 0.61 & 0.69 \\
\hline Plaiticine & $2 \cdot 1 / 2$ & Diamond & $w-2$ & Wood & 8 & 80 & 1.28 & 1.42 & 0.58 & 0.73 \\
\hline \multirow[t]{2}{*}{ Uranium } & $1-7 / 16$ & Diamond plus & $\mathrm{Sl}_{1}(\mathrm{e})_{4}+\mathrm{Sg}$ & Steel & $8+5$ & & & & & \\
\hline & & hand round & s-4 & Steel & 5 & 90 (total) & 1.10 & 1.20 & 0.83 & 0.96 \\
\hline \multirow[t]{2}{*}{ Masticine } & $2 \cdot 1 / 2$ & Diamond plue & $w-2$ & Wood & 8 & & & & & \\
\hline & & hand round & $w-4$ & Wood & 11 & 88 (total) & 1.07 & 0.88 & 1.00 & 0.97 \\
\hline
\end{tabular}

(a) See Figures 2 and 3

(b) Ratio of tadial dimension to width perpendiculat to radius

(c) Reduction in thicknes, four passes at roll settings of $1,22,1,10,0,98$, and 0.90 in.

(d) Reduction in thicknet. four passes at toll settings of $2.125,1.94,1.69$, atid 1.56 in

(e) Diamond grooves only. 


\section{CONFLENTIAL}

21
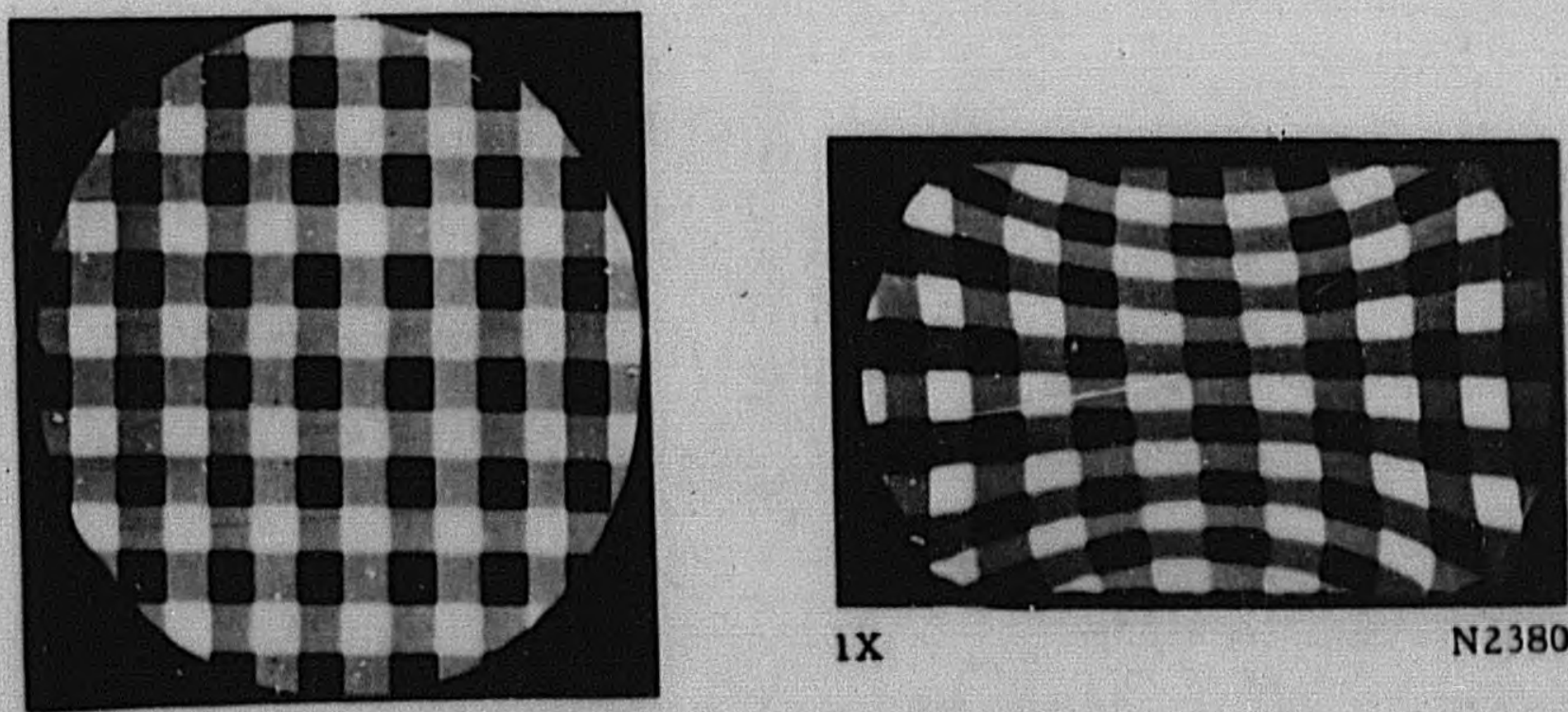

IX

N23806

IX

N23805

Plasticine
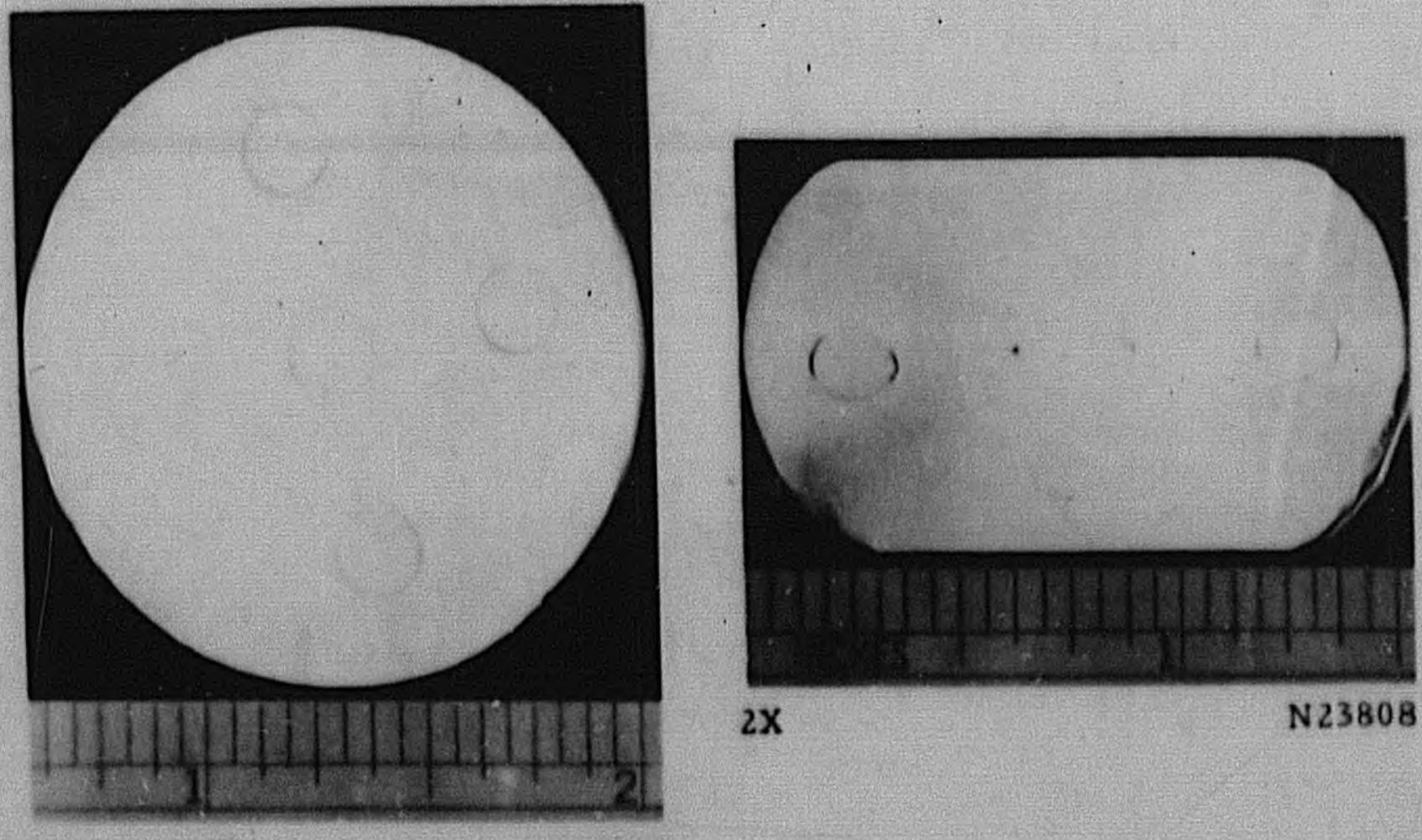

$2 \mathrm{X}$

N23807

\section{Uranium}

FIGURE 8, SECTIONS OF COMPOSITE PLASTICINE AND URANIUM INGOTS PRIOR TO ROLLING (LEFT) AND AFTER FOUR BULLHEAD PASSES (RIGHT) 


\section{CONFIDENTIAL}

\section{2}
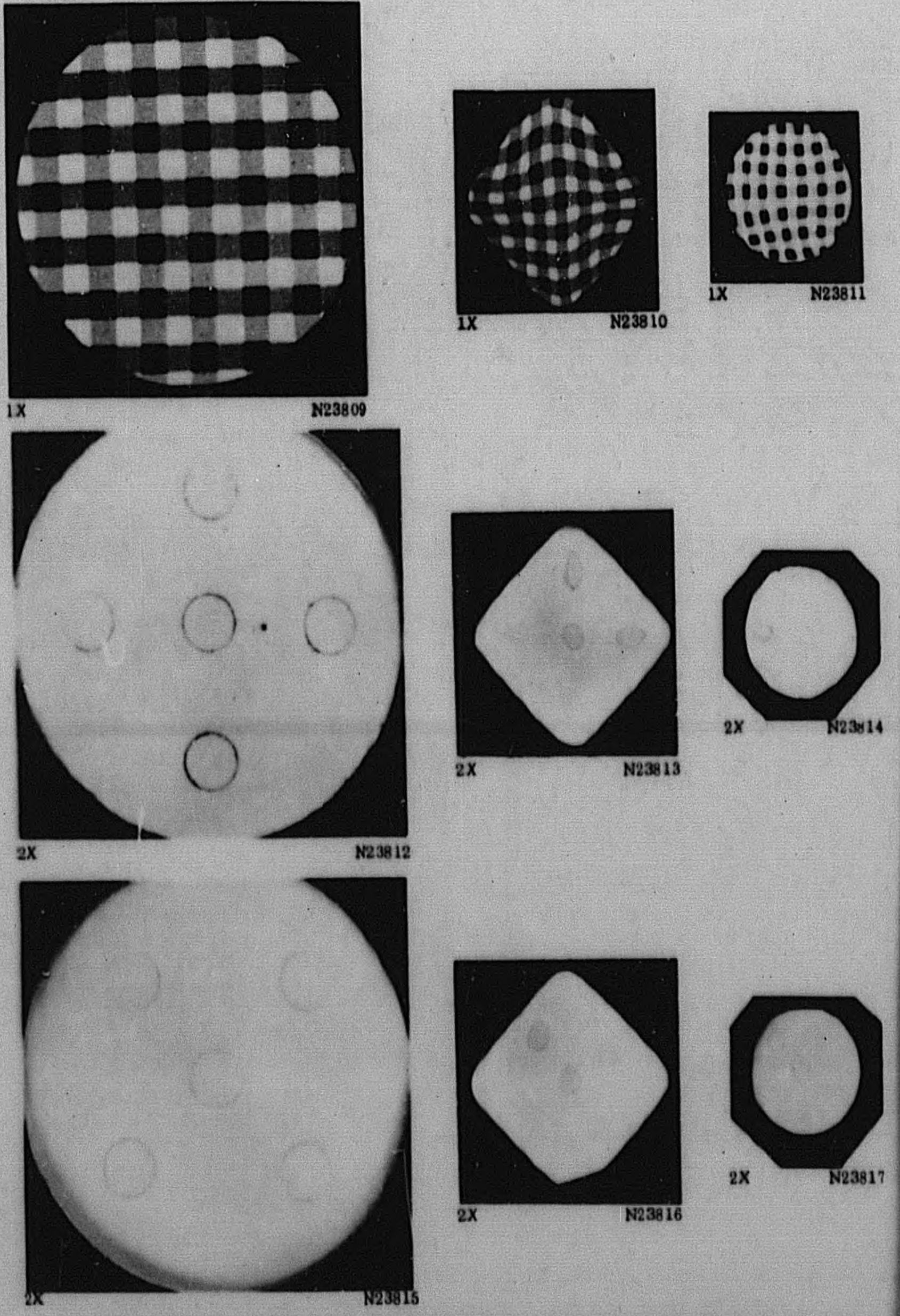

$2 X$

N23812
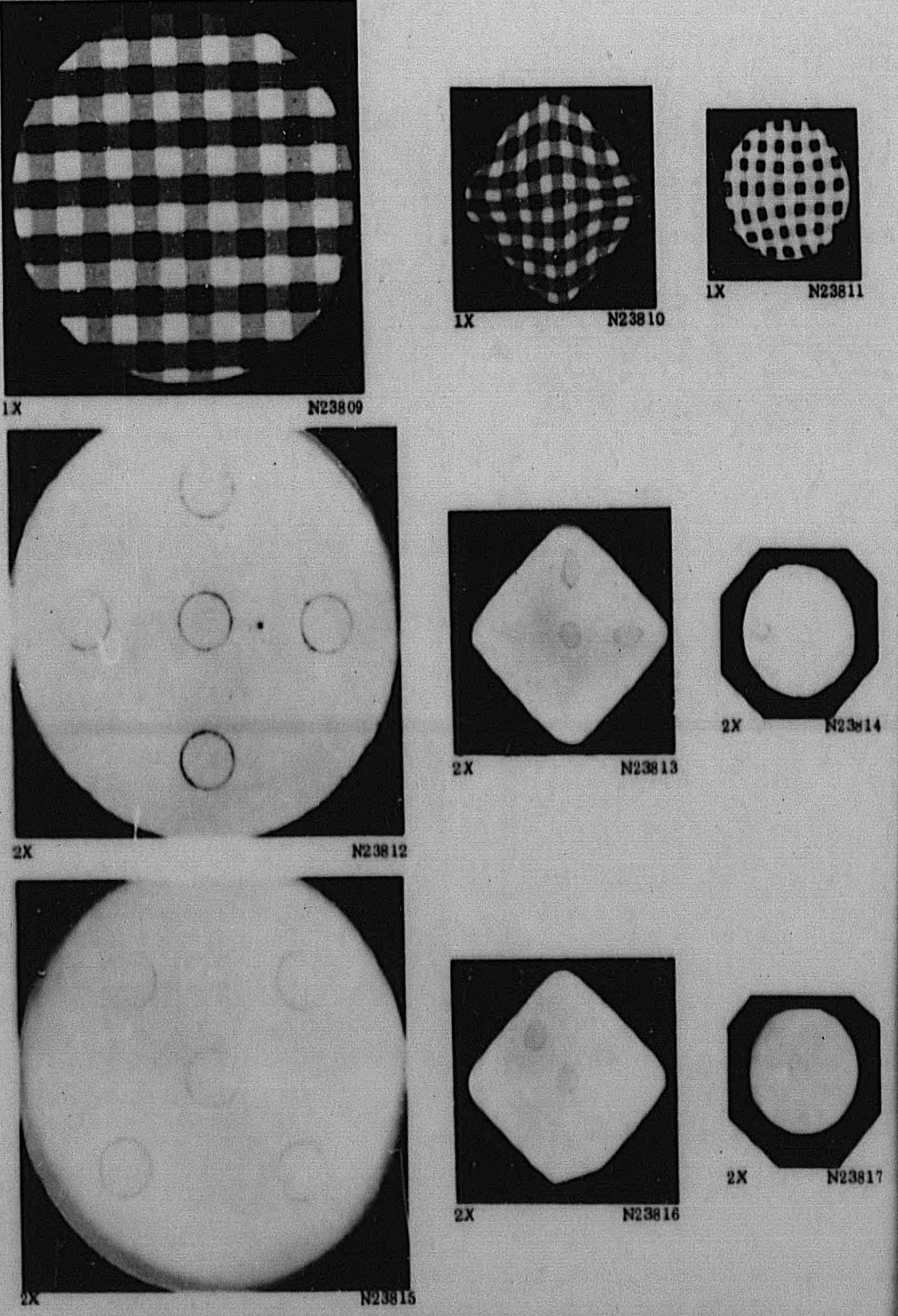

FIGURE 9. SECTIONS OF COMPOSITE PLASTICINE INGOTS (TOP) AND COMPOSITE URANIUM INGOTS
(CENTER AND BOTTOM); PRIOR TO ROLIING (LEFT), AFTER REDUCTION IN DIAMOND

FIGURE 9. SECTIONS OF COMPOSITE PLASTICINE INGOTS (TOP) AND COMPOSITE URANIUM INGOT
(CENTER AND BOTTOM); PRIOR TO ROLLING (LEFT), AFTER REDUCTION IN DIAMOND GROOVES (CENTER), AND AFTER FURTHER REDUCTION IN HAND ROUNDING GROOVES (RIGHT)

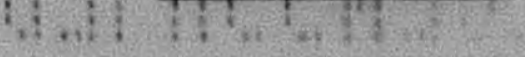




\section{CONFLDENTIAL}

The amount of deformation as indicated by the change in height and width of the segments also showed good agreement, although, as is indicated previously, the two materials were rolled in different sets of rolls.

One direct comparison between the two materials was made. A composite uranium ingot containing a zirconium grid was rolled in the diamondoval-round series, Roll S1, Figure 3, and a Plasticine ingot was rolled in these same rolls. The shape of the $g$ rid and lamina after the first three passes and in the finished rod is shown in Figure 10. Both materials show an $\mathrm{S}$-shaped flow resulting from the orientation of the square on catry into the oval groove, but no quantitative data were obtained.

\section{PLASTICINE FLOW PATTERNS}

After establishing the general similarity of flow in Plasticine and uranium, the flow characteristic of Plasticine in the FMPC breakdown rolls and diamond grooves as well as in several additional groove shapes was investigated. The additional shapes included: (1) the complete FMPC schedule of breakdown plus finishing grooves, (2) oval-round reductions, and ( 3 ) handround reduction.

Several samples were also rolled to investigate the effect of the initial shape of the ingot on the flow in various grooves.

\section{FMPC Breakdown Rolls}

Figure 11 is a composite photograph prepared from the negatives of Figures 5 and 7 and shows the lateral deformation of initially square segments of area in the billet at various stages in the reduction. All of the photographs are oriented on the page so that the initial vertical axis in the first pass is vertical, and the same segment of area is at the top in each photograph. Since the bars are turned 90 deg between grooves, the compression axis in the photographs changes from vertical to horizontal in each succeeding view.

The shapes and dimensions of the segments indicate that during bullheading the center portion of the ingot is compressed and spreads laterally. Segments near the rounded edges tend to remain nearly square. On the vertical axis through the center of the bullheaded section, the elements at the center spread more than segments near the roll surface where roll friction tends to restrict the lateral movement. The edger passes work the material in the opposite direction and tend to return the segments to a square shape; however, some lateral spread persists after the third edger reduction. 


\section{CONFIDENTIAL}

24
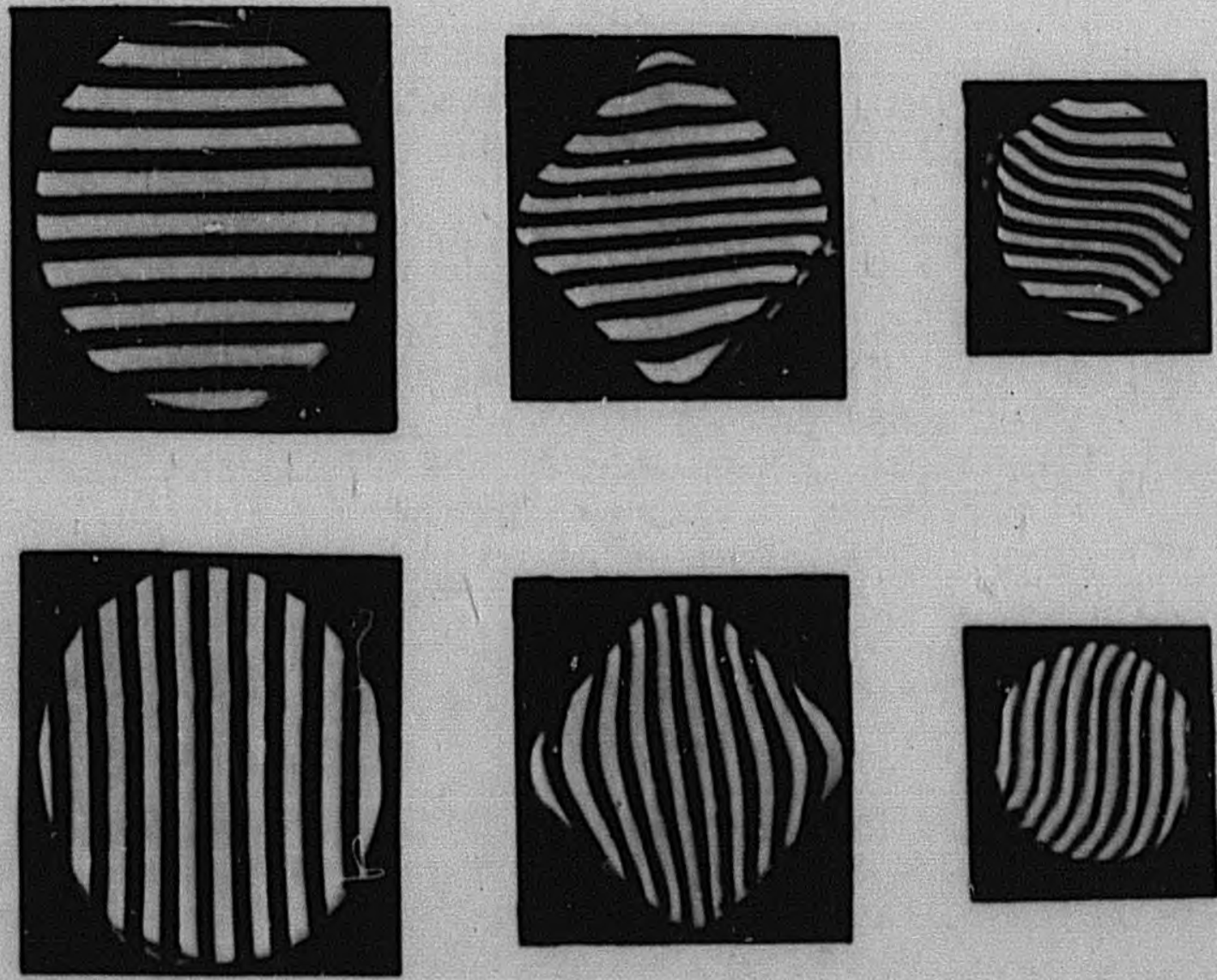

IX

N15829

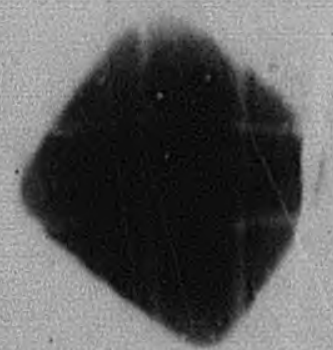

IX
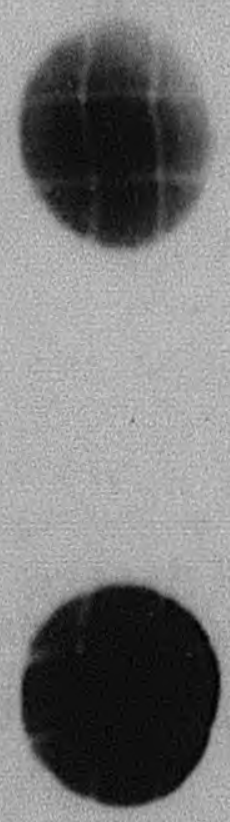

Radiograph

FIGURE 10. SECTIONS OF COMPOSITE PLASTICINE INGOTS (UPPER) AND URANIUM INGOTS (LOWER) AFTER TWO STAGES OF ROLLINC THROUGH THE 8-IN. MILL, DIAMOND-OVALROUND GROOVES

\section{CONFIDENTIAL}

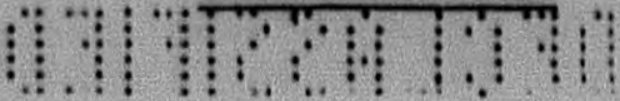



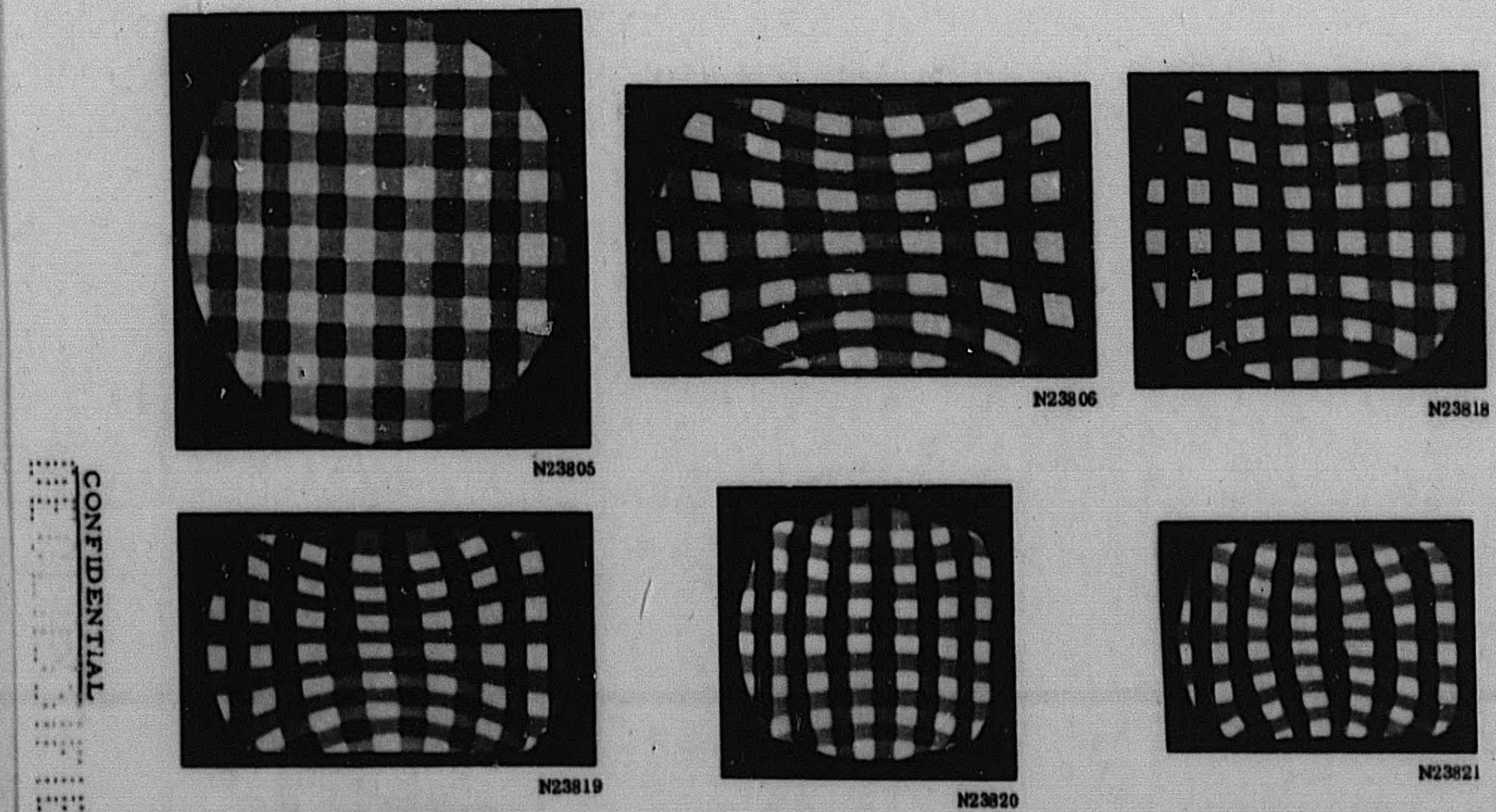

ง
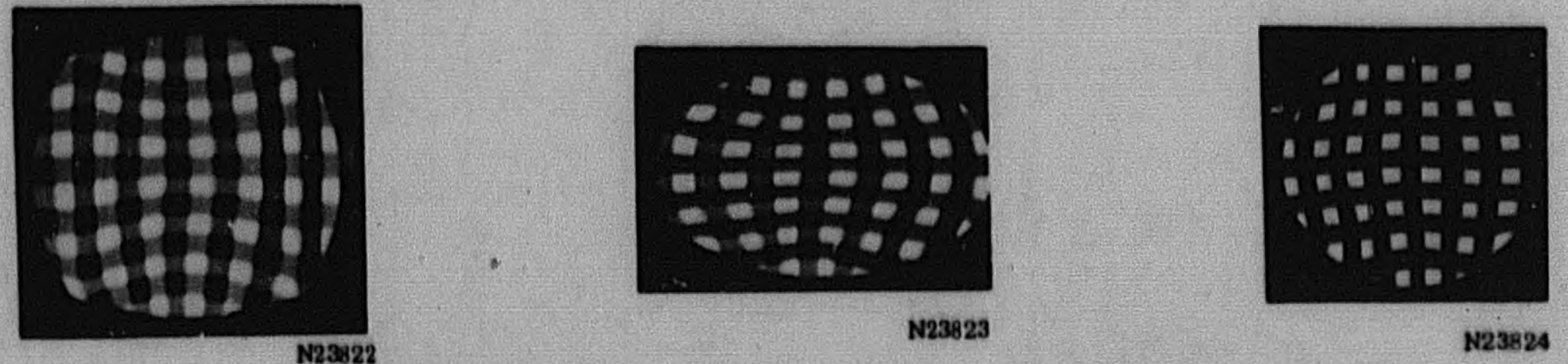

FIGURE 11. COMPOSITE PHOTOGRAPHS OF SECTIONS OF THE ORIGINAL. INGOT AND ROD SHOWN IN FIGURES 5 AND 7 


\section{CONFIDENTLAL}

\section{6}

The oval pass following the third edger produces the greatest amount of nonuniform deformation. Spread in this pass is severely restricted at the roll surface by the shape of the roll, and occurs primarily along the horizontal axis. The final pass again reverses the flow and results in a more nearly uniform shape in the segments.

With the exception of segments lying on, or close to, the horizontal and vertical axis, the direction of flow is not parallel to these axes. Elements located in the area between the axes assume a rough parallelogram shape indicating the direction of $\mathrm{Alw}$. A reversal in the direction of flow in these areas occurs in the first oval groove.

In addition to round billets, a 2-1/2-in, - square billet and a billet shaped similar to the bullheaded round were rolled in these roughing rolls. The latter billet was entered directly into the first edger pass and subsequently rolled on the same schedule as round billets. The flow was not sigaificantly changed by eliminating the first bullhead reduction. Although there was slightly less lateral flow evident in the initial stages of the reduction, the final oval rod had an almost identical flow pattern to that of an initially round bịllet.

The square billet was rolled on the same schedule as the round billets and reduced more uniformly in the initial bullhead pass. Subsequent edging, however, resulted in flow lines similar to those obtained with a round billet. In succeeding passes, the flow patterns observed with both square and round ingots were quite similar.

\section{FMPC Finishing Grooves}

After the initial breakdown at FMPC, the oval billet is reheated and finish rolled in a series of six oval-round groove.. Figure 12 shows the flow pattern in an oval billet finished in this series of grooves. Also shown are

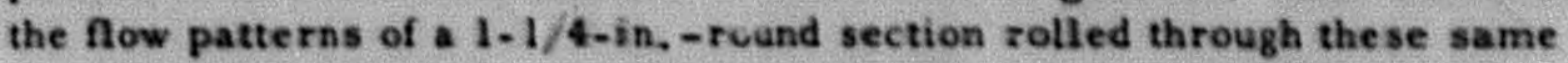
grooves. Composite photographs of both rods are shown in Figure 13.

The flow in the oval groove was similar to that previously observed in the oval on the breakdown rolls. Most of the lateral spread occurred on the major axis of the oval, and the spread at the roll surface was restricted. The subsequent round groove reversed the direction of flow and produced an undistorted square pattern in the final rod. The shape of the starting billet had little effect on the final Ilow pattern. Both the oval billet from the FMPC breakdown and the round ingot showed similar deformation patterns, although in the first oval groove, the FMPC billet failed to fill the groove completely. Subsequent round and oval passes filled satisfactorily and the final round section had essentially undistorted square segments similar to those obtained with the round ingot. 


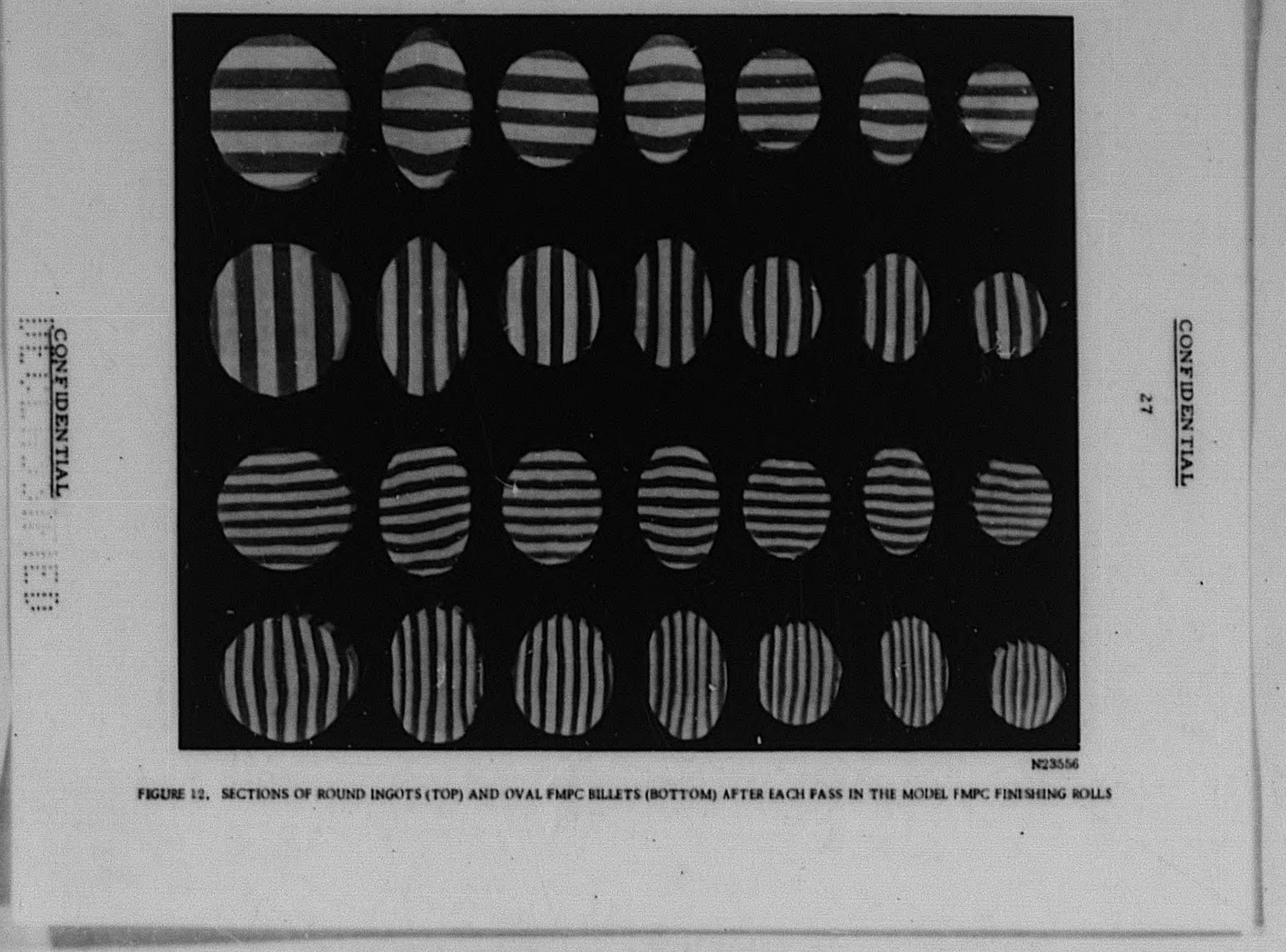



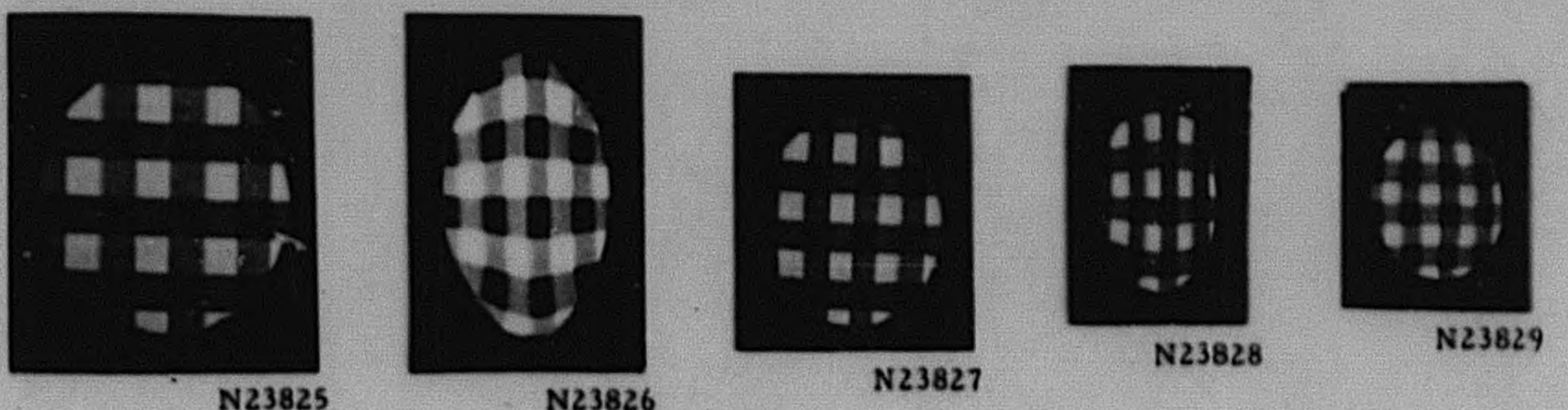

N23825

N23826 N23827

N23828
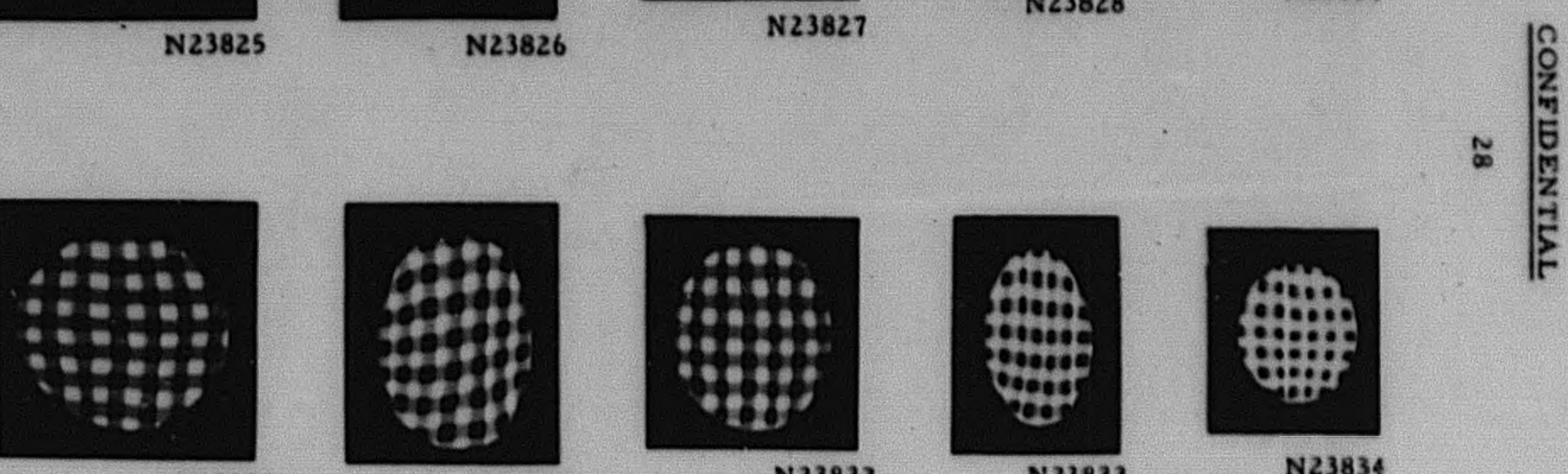

N23830
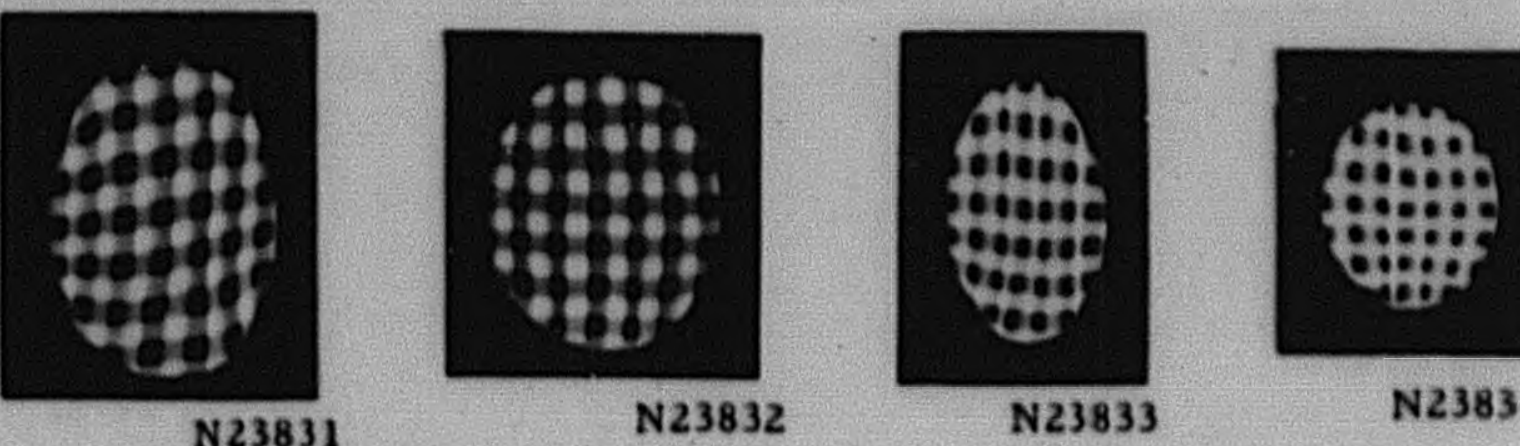

N23834

FIGURE 13. COMPOSITE PHOTOGRAPHS OF SOME OF THE SECTIONS OF THE INGOTS SHOWN IN FIGURE 12 


\section{CONFIDEN TLAL}

\section{Diamond Grooves}

Sections of 2-1/2-in, -diameter laminated ingots which were rolled through the diamond grooves ( $W-2$, Figure 2$)$ are shown in Figures 14 and 15. A composite photograph is shown in Figure 16. The ingots were passed twice through each groove, being turned 90 deg after each pass. The total reduction in area was 80 per cent.

The first groove did not fill completely and only slight distortion of the initially square segments occurred. The second pass, however, filled completely, and the lateral now on the diagonal axis of the diamond rod is readily apparent in subsequent grooves. As indicated in the previous discussion on the flow of uranium in similar diamond grooves, the Now adjacent to the flat sides of the diamond was parallel to these faces.

The deformation pattern in a 1-3/4-in, - square billet rolled in these diamond grooves is shown in Figures 17 and 18 . These ingots were entered in the fourth groove and rolled from that point in the same manner as the round ingots. The total reduction in area was 73 per cent.

The deformation was much more uniform than that obtained with round ingots. The lamina remained nearly straight and parallel, particularly the lamina in the horizontal direction.

In comparing the reduction. of initially round and square ingots in diamond grooves, it is evident that the distortion or nonuniform lateral flow observed with the former is the result of the change in shape. The nonuniform flow occurs in the initial passes where the shape is changed from a round to a diamond. Subsequent reductions do not materially alter the shape of the lamina.

\section{Hand-Rounding Grooves}

The hand-rounding grooved (see Figure 2) were modeled after the finishing grooves at Simonds Saw and Steel Company. The reduction in these groover is only 33 to 38 per cent compared to a total reduction of 45 per cent during finishing at Simonds. This is the result of omitting the final groove because of lack of space on the wooden roll body.

The deformation of diamond billets produced in the diamond breakdown rolls, and of 1-1/8-in.-diameter ingots in these rolls is shown in Figure 19.

The round ingot was reduced quite uniformly and both vertical and horizontal lamina remained straight and parallel. 


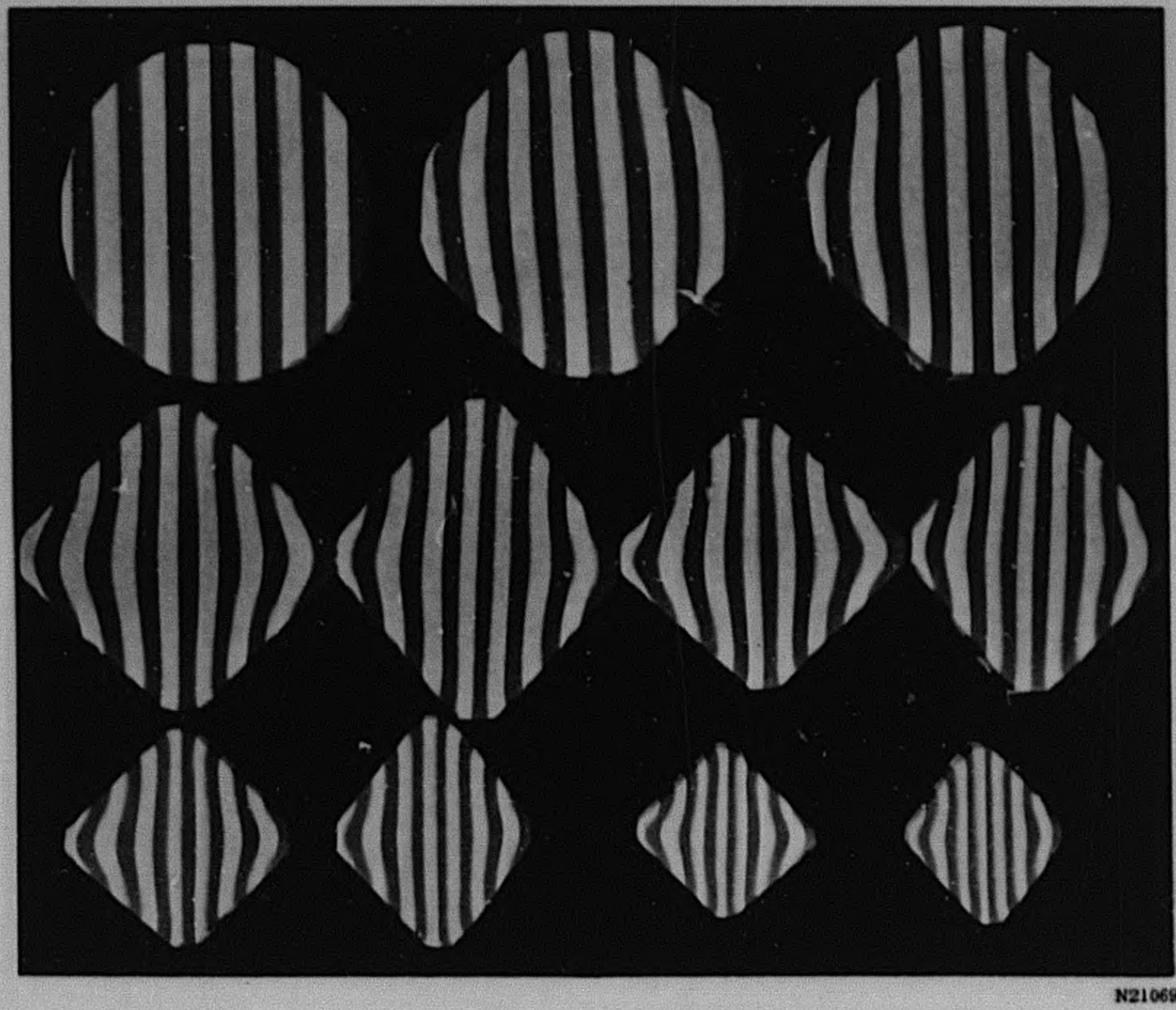

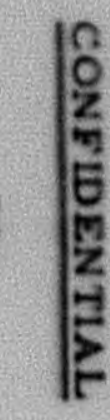

FIGURE 14. CROSS SECTIONS OF $A$ 2-1/2-LN, -DLAMETER INCOT AND ROD AFTER FIRST AND SECOND PASSES THROUGH THE FIRST, THERD, FOURTH, SEXTH, AND EGHTH GROOVES OF THE MODEL SMMONDS BDUGHING ROLLS 


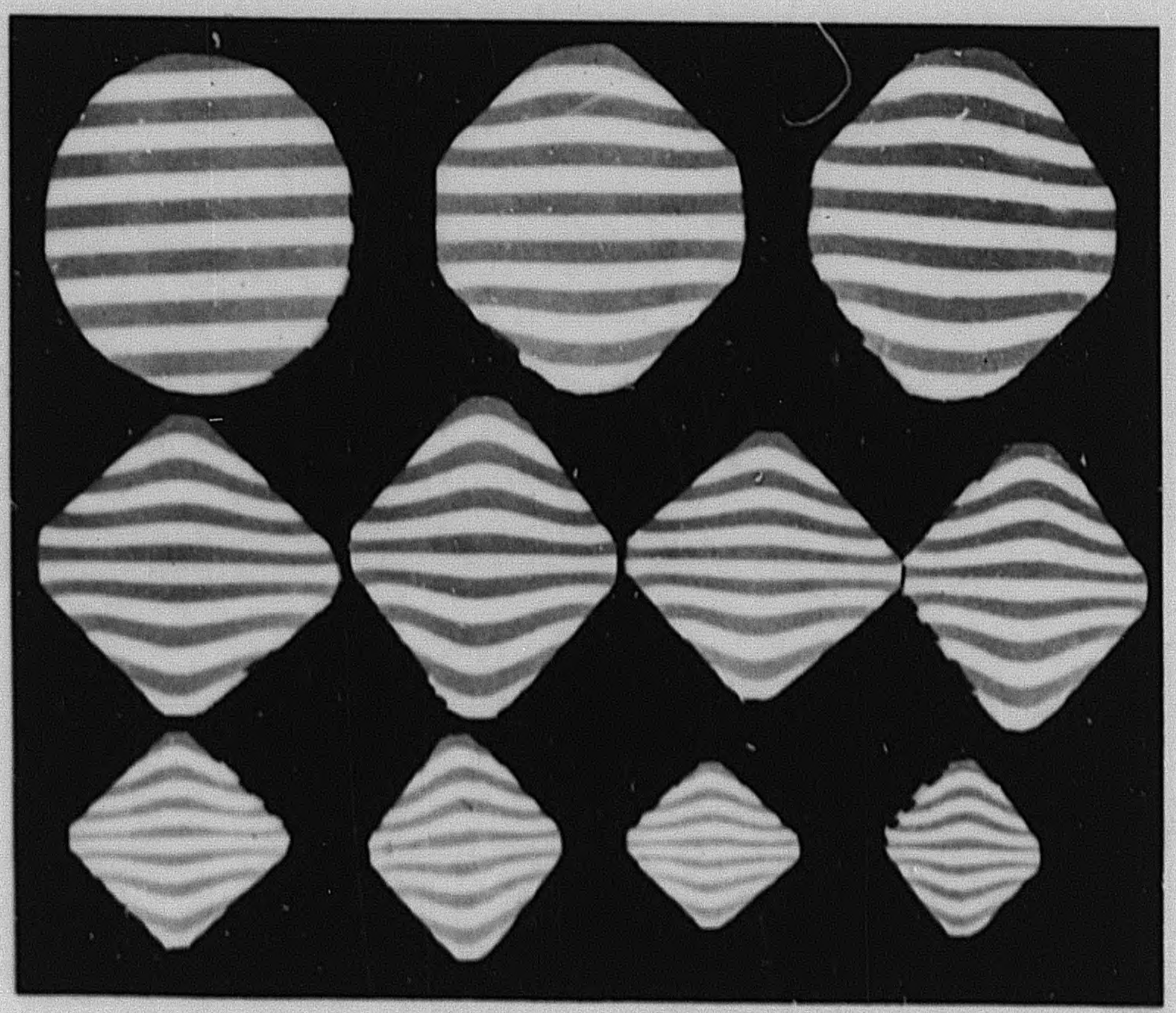

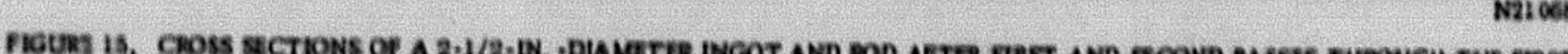

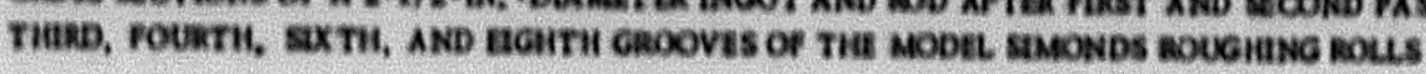


:...::

i...:.:

.......

….......

$\because: 0$

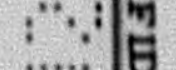
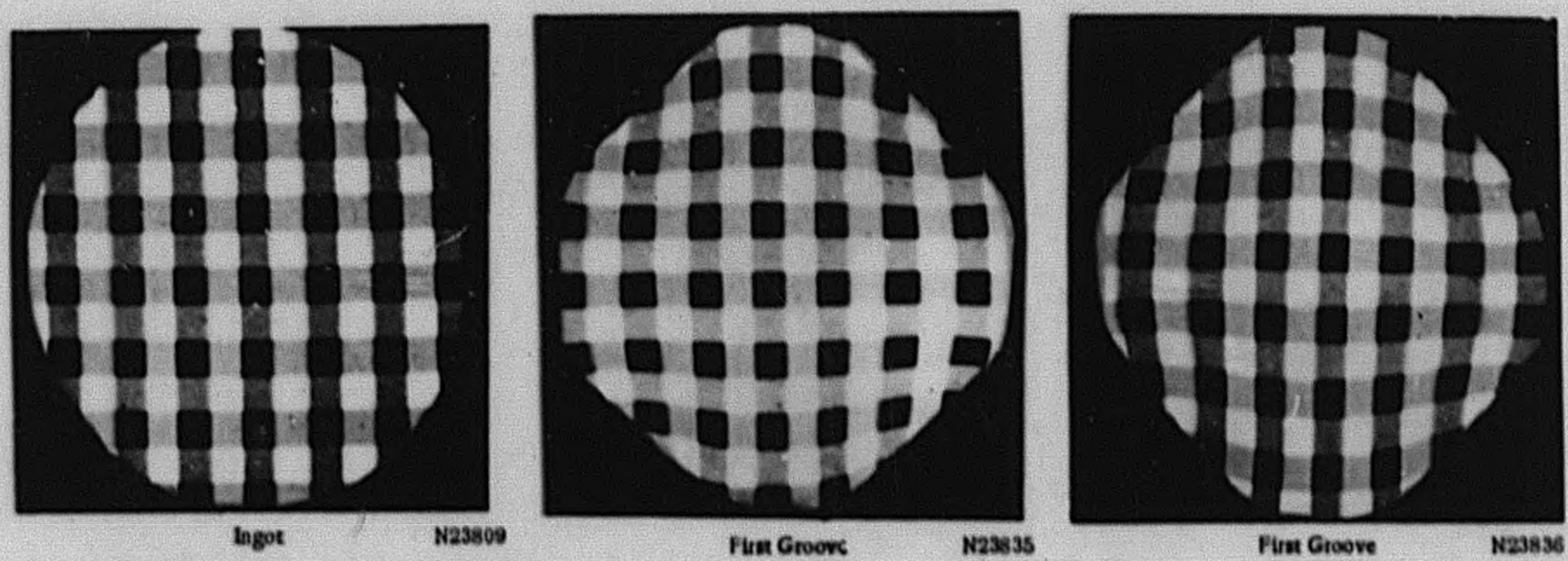

$\therefore . . .$.

i...:.

:......
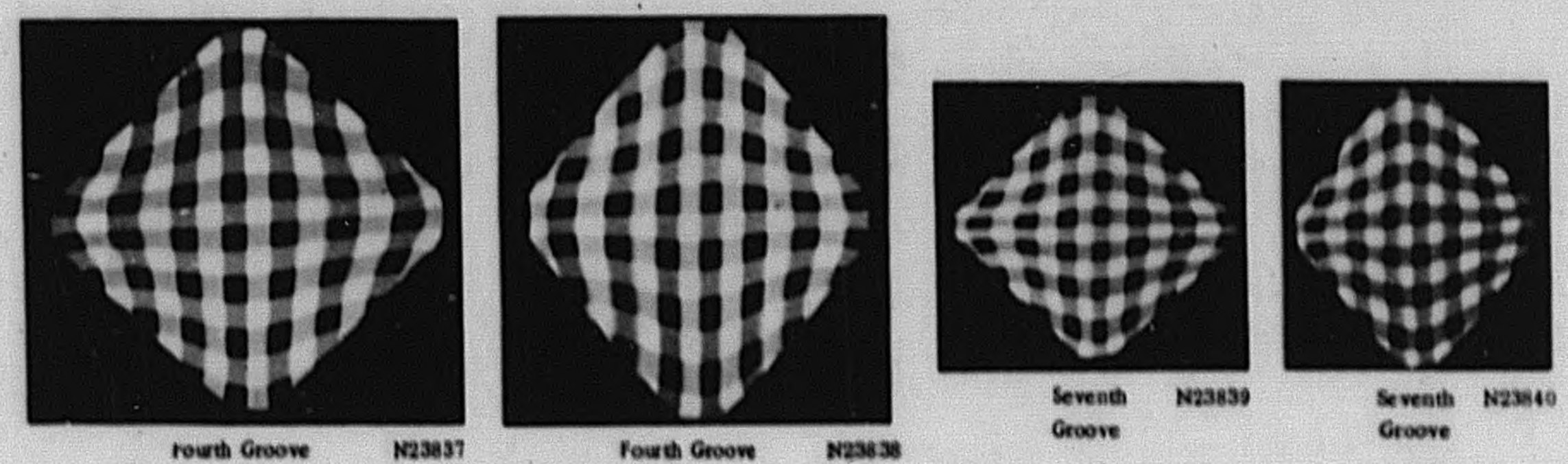

$\approx$

|

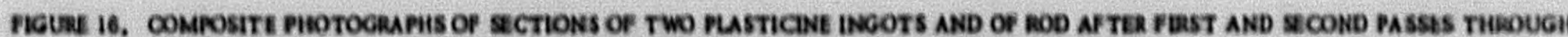
THE FUST, FOURTM, AND SEVENTH GEOOVES OF THE MODEL SAMONDS ROUGHENG ROLLS 


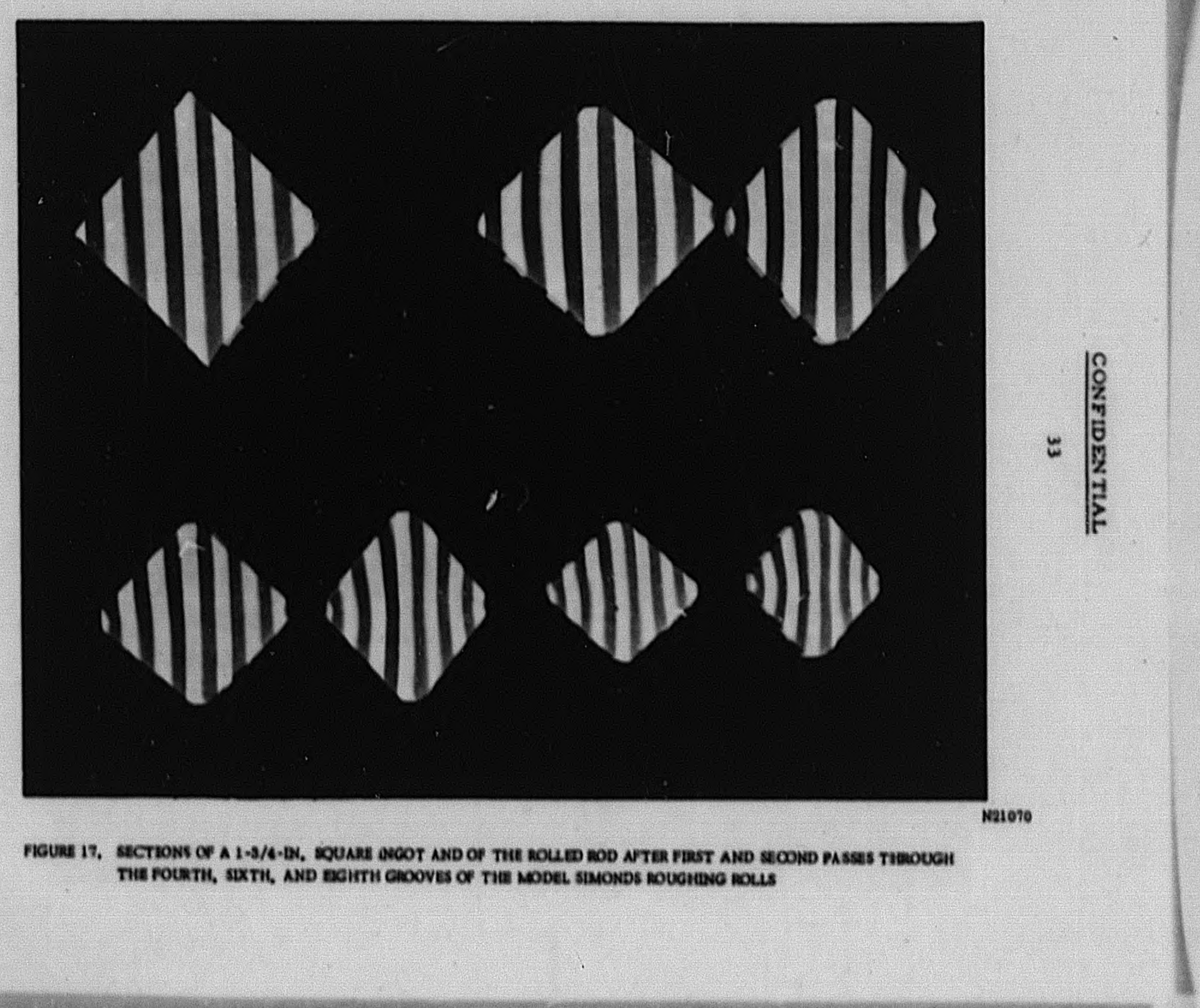




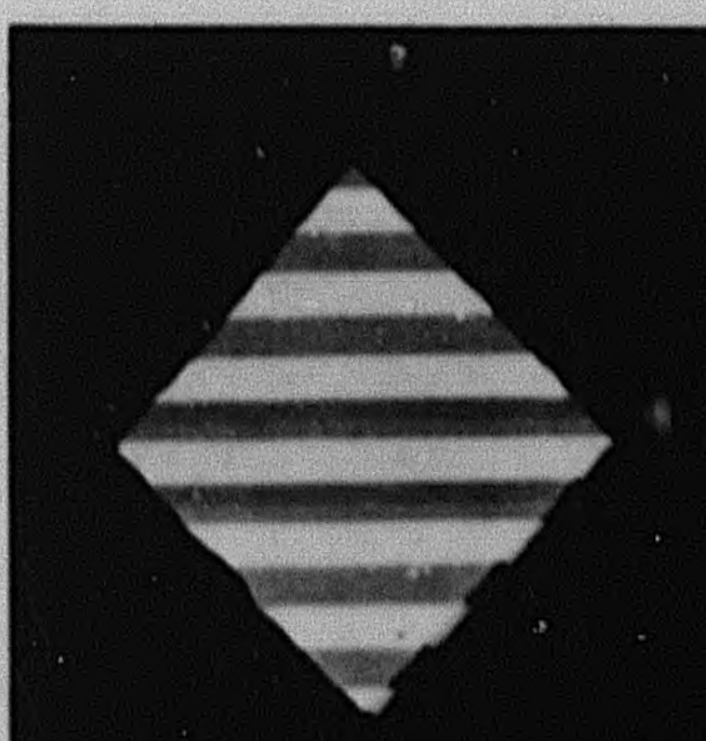
.....:

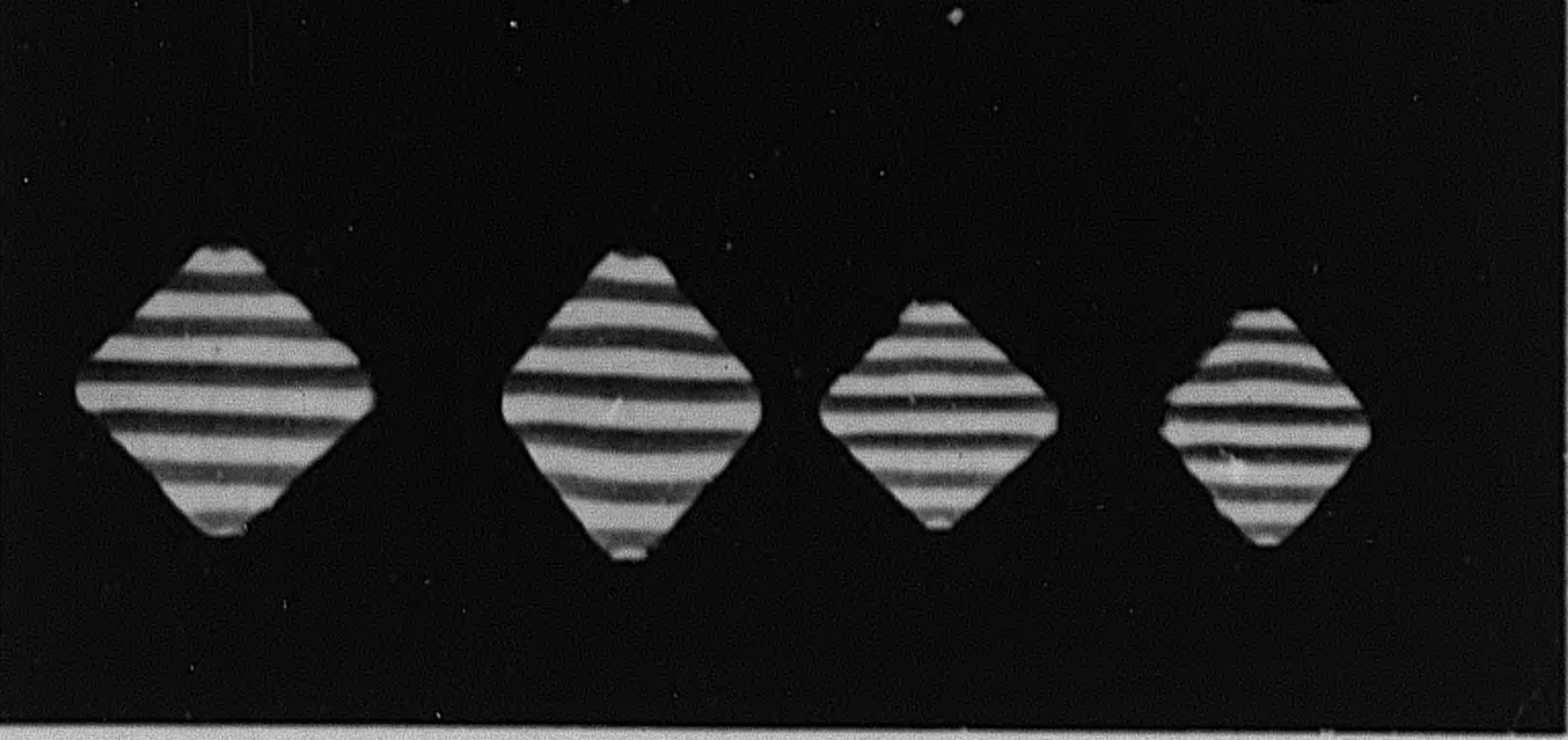

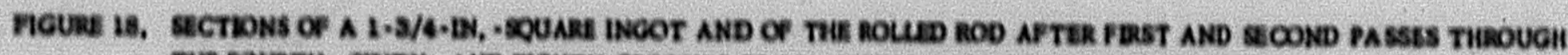

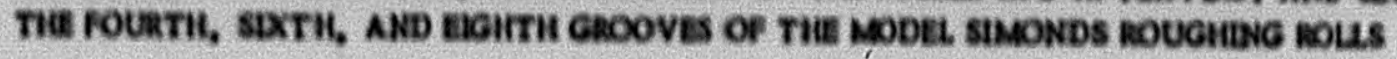



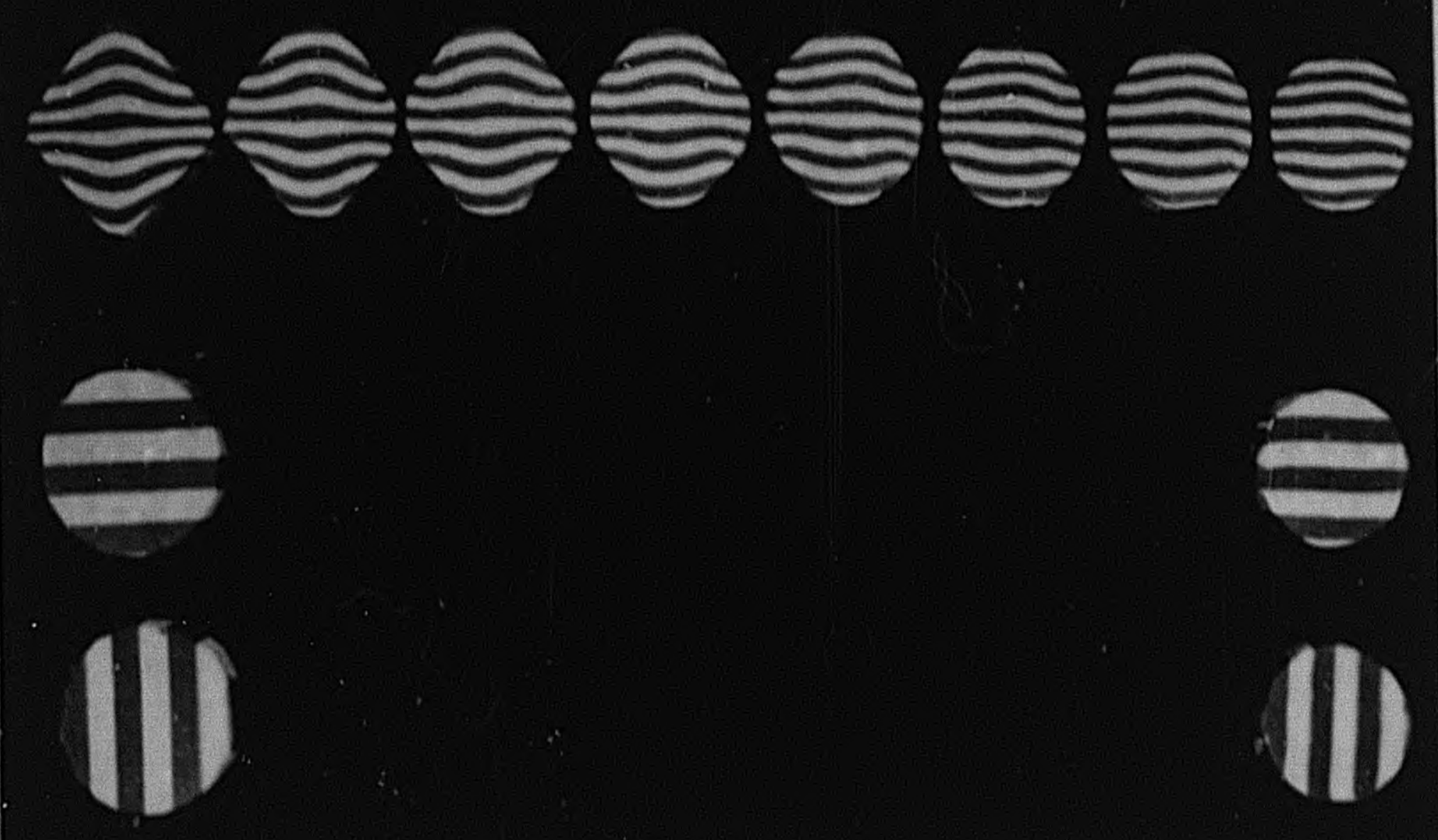

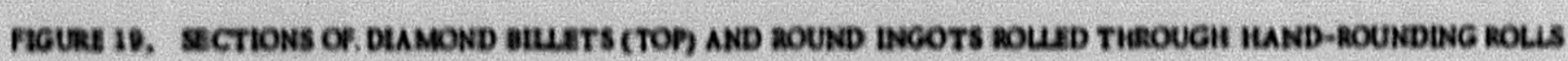




\section{CONFIDENTLAL}

36

The flow in the diamond billet produced from a round ingot was such that the curved lamina produced by the breakdown tended to straighten in the hand-round reduction. The resulting flow pattern in the final round rod lvoked quite uniform, Both horizontal and vertical lamina were nearly straight and parallel after the final pass. There is some unsymmetrical distortion in the shape of the lamina which is probably the result of entering the rod into the groove with the lamina cocked at an angle to the vertical axis.

\section{CORRELATION OF PHYSICAL PROPERTIES OF} URANIUM AND PLASTIC FLOW

A limited study of the crystallographic orientation of uranium in small local areas of the cross section of rolled rod was made in an effort to corre. late the orientation with the direction of lateral flow. Thermal-expansion measurements also were made in selected radial directions to determine whether the effect of lateral flow could be detected. Similarly, the ultrasonic transmission characteristics of an FMPC rolled rod were measured with reference to the vertical axis of the rod in the final groove.

\section{X-Ray Diffraction Studies}

Selected areas in three types of rod were examined by X-ray diffraction, and the amount of preferred orientation estimated by the method described by Harris $(5)$. The rods examined were the FMPC oval b.llet, the FMPC finished rod, and a diamond-shaped rod rolled at Battelle. The former FMPC rods were rolled under normal FMPC production conditions except that the vertical axis in the final pass in the finishing zolls was marked for a reference point. The diamond rod was a solid section of the same rod which contained the inserts shown in Figure 9. This rod was rolled at 1150 to $1175 \mathrm{~F}$ to a total reduction of 80 per cent.

In order to confine the area examined to as small a cross section as possible, the samples were not rotated or moved during the X-ray examination. The grain size of the uranium was small, $0,02 \mathrm{~mm}$, and the results obtained from separate runs on adjacent areas were in fair agreement. However, some anomalies were observed which may have been caused by the relatively small number of grains exposed to the $X$-ray beam.

Figure 20 shows the method of sectioning each rod and the areas examined. Inverse pole figures for each of the areas are shown in Figures 22 to 24. Each quadrant on the stereographic net represents a separate area of the rod. The intensities of the various poles relative to the 

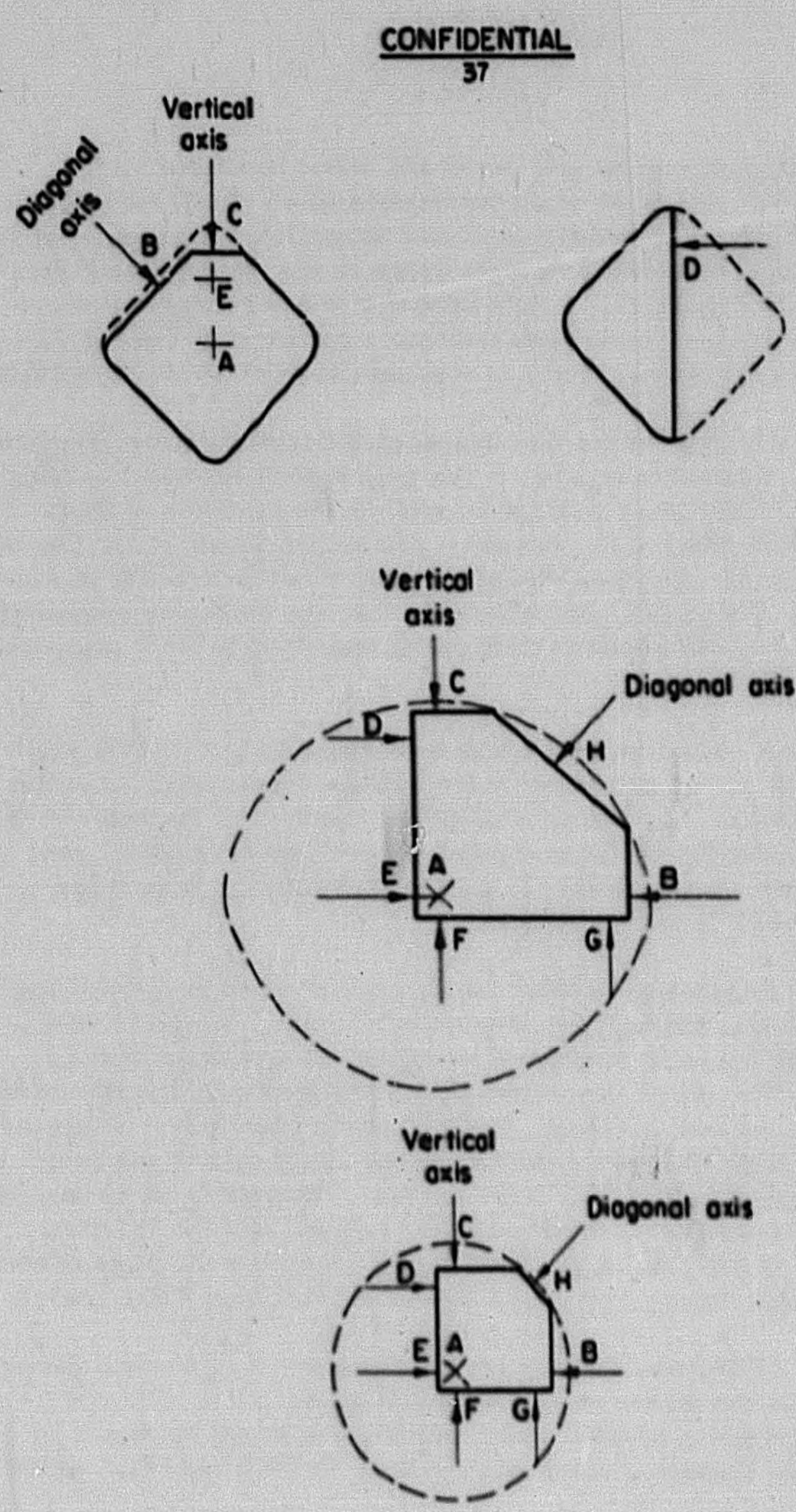

FIGURE 20. SECTIONS CUT FROM A DIAMOND-ROLLED ROD(TOP), AN FMPC BILLET (CENTER), AND AN PMPC FINISHED ROD (BOTTOM), INDICATING THE' LOCATION OF THE SURFACES EXAMINED OY $X$-RAY DIFFRACTION 


\section{CONFIDENTLAL}

38

intensities for a random sample are shown and were calculated by the method of Mueller(6). Because of the limitations of the North AmericanPhillips Geiger counter X-ray diffraction unit using CuK radiation, only 18 unequivocally indexed reflections of the se poles on the stereographic projection are shown in Figure 21. A pole intensity of five corresponds to a random orientation, higher intensities indicate a concentration of the pole. Contour lines were arbitrarily drawn to separate several levels of intensity.

The direction of flow in the diamond-shaped bar was previously shown by the shape of the inserts in this bar. The pole figures for this bar indicate a tendency for the $(002)$ planes to align parallel to the direction of flow. Thus, a concentration of the $(002)$ poles was observed perpendicular to the flat faces and perpendicular to the diagonal axis of the rod, Position B and D in Figure 20. In the axial direction, Positions $A$ and $E$, the (041) pole showed the highest concentration with a relatively high concentration of $(110)$ poles nea $r$ the surface at Position E.

The FMPC oval-billet showed a high concentration of the (002) poles perpendicular to the major axis close to the surface Position G; but at the center, where a similar concentration would be expected on the basis of the flow patterns, Position $F$, the highest pole concentration was (011). An anomaly exists at the center where the pole concentrations in the three orthogonal directions are not consisient.

A smaller concentration of $(002)$ poles was also found perpendicular to the minor axis and near the surface, Position D. Some concentration of these poles also was found at Position $\mathrm{H}$ which is at the surface midway between the axes. The latter concentration is consistent with the Plasticine flow pattern in the two oval grooves. The Plasticine flow pattern indicates a gradual transition from flow perpendicular to the minor axis at the center of the rod to flow parallel to this axis at the surface. However, the amount of flow indicated at the surface of the Plasticine is slight, and the relatively high concentration of (002) poles observed in the uranium at Position D may be the result of slight finning which may have occurred in the final groove.

The finished FMPC round also showed a tendency to have (002) planes aligned parallel with the direction of flow except at the center of the rod. Thus, a high concentration of (002) poles was found at Positions B and D but at Position E the highest concentration was of the $(011)$ and $(023)$ poles.

The principal conclusions resulting from these limited X-ray diffraction studies were that there is a nonuniform radial distribution of preferred orientation and that there is a tendency for the (002) planes to align parallel to the direction of lateral flow near the surface of the rod. The orientation at the center of the rod could not be correlated to the flow pattern. 


\section{CONFIDENTIAL \\ 39}

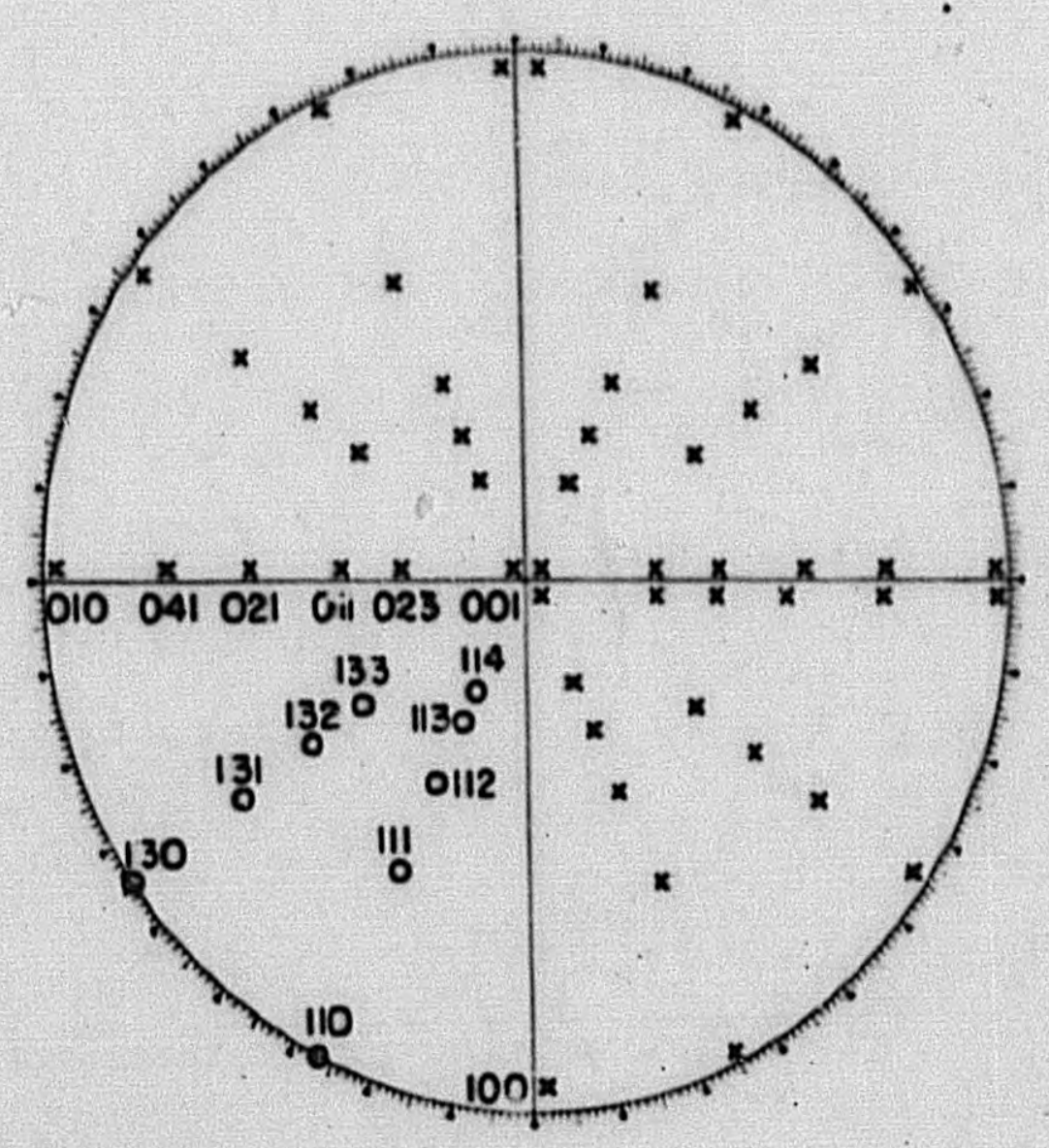

FIGURE 21. STEREOGRAPHIC PLOT FOR THE (OOI) PROJECTION OF ALPHA URANIUM 


\section{CONFIDENTIAL}

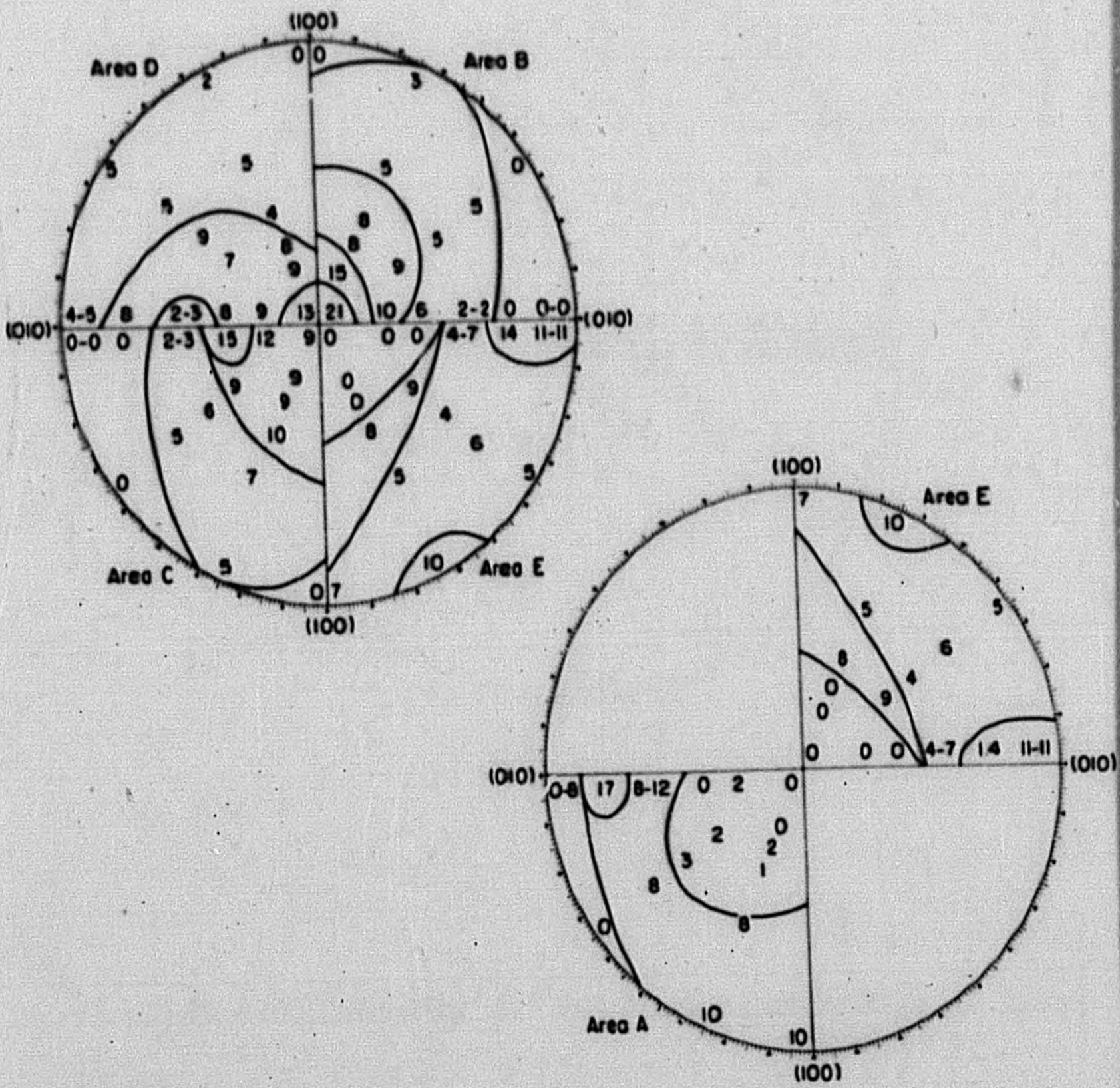

FIGURE 22. INVERSE POLE FIGURES FOR THE FIVE POSITIONS INOICATED ON THE BATTELLE-ROLLED DIAMOND URANIUM BAR

\section{CONFIDENTIAL}



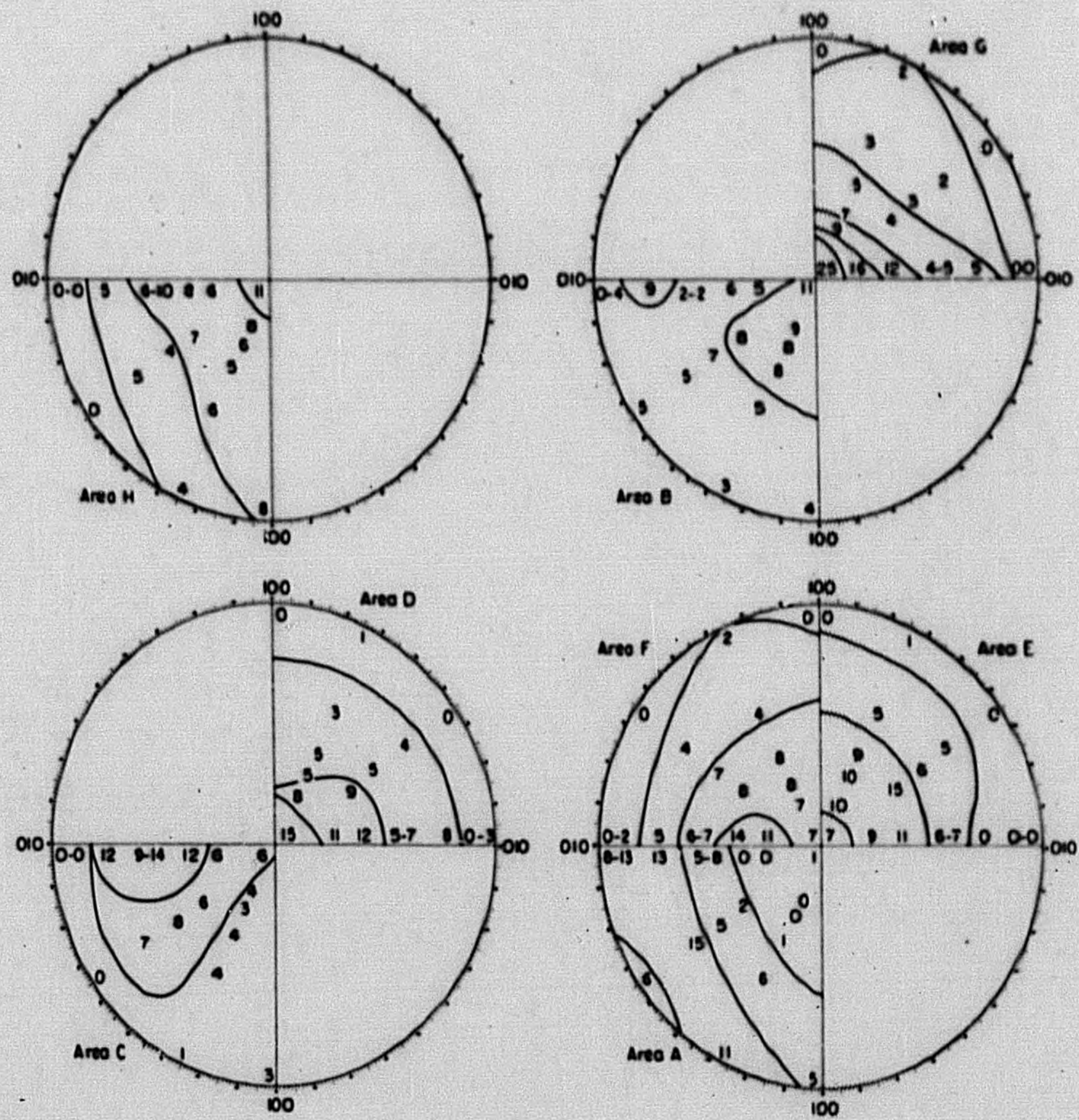

FIGURE 23. INVERSE POLE FIGURES FOR THE EIGHT POSITIONS INDICATED ON THE FMPC OVAL URANIUM BILLET 


\section{CONFIDENTIAL}

\section{2}
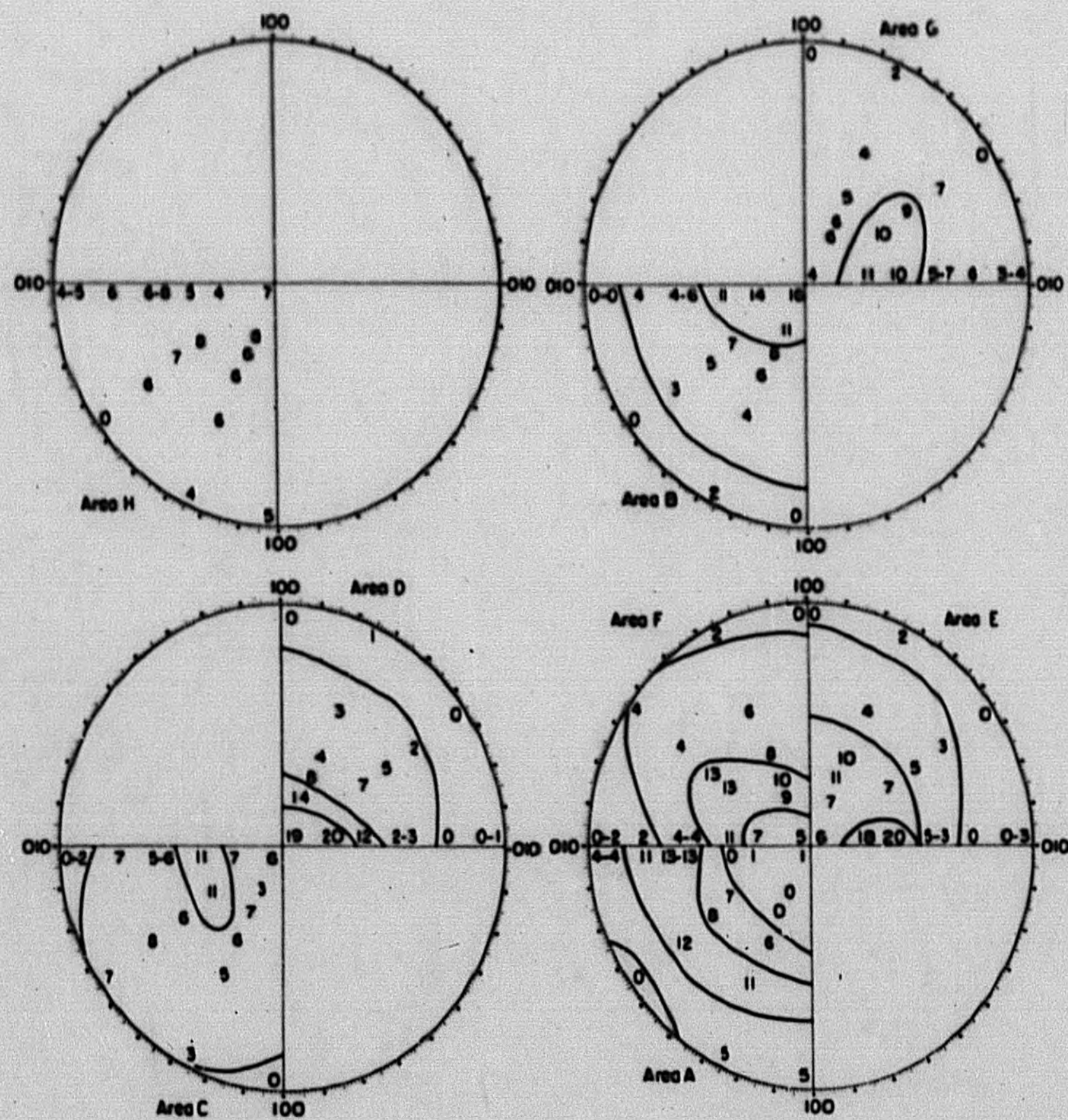

FIGURE 24. INVERSE POLE FIGURES FOR THE EIGHT POSITIONS INDICATED ON THE FMPC FINISH-ROLLED ROUND URANIUM ROD

\section{CONFIDENTIAL}

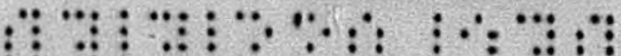




\section{CONFIDENTIAL}

43

\section{Thermal-Expansion Measurements}

Dilation tests were run on specimens cut in different directions in a diamond-rolled uranium rod in an effort to determine whether the direction of flow caused a significant change in the thermal-expansion characteristics.

Specimens $1 / 8$ in. square and $7 / 32$ in. long were cut as shown in Figure 25 and the thermal expansion in the two radial directions measured. The deformation of inserts in a similarly rolled rod indicated that the principal flow occurred parallel to the direction of measurement in one case and perpendicular to the direction of measurement in the other.

The thermal expansion between $35 \mathrm{C}$ and $150 \mathrm{C}$ was measured in an interferometer by the method described by Merritt(7) and the results are shown in Figure 26. No difference between the two samples could be detected. Both samples had a coefficient of expansion of 17.5 by $10-6 \mathrm{in}$, / in. / c.

Although the samples were as small as practical, the area covered was a significant part of the cross section and the effect of flow in the small segments of area near the surfaces may, therefore, have been obscured. However, the results indicate that gross differences in thermal expansion coefficients in the two directions are not produced by differences in the lateral flow.

\section{Ultrasonic-Transmission Properties}

The ultrasonic-transmission properties of several sections of the FMPC rolled uranium rod were measured using 1 -megacycle ultrasonic energy. The specimens were submerged in water with the transmitting and receiving crystals placed diametrically opposite; the ultrasonic beam was transmitted by a 1 -in, - square crystal and received by a 1/4-in, -square crystal. The strength of the received signal was indicated by the height of the peak observed on a cathode-ray oscilloscope.

Initial studies were made on a machined reject slug received from FMPC. The slug was rotated through 360 deg between the crystals, and the relative strengths of received energy were plotted on polar coordinate paper. This test was repeated at three points along the length of the bar. Results from one of these positions are shown in Figure 27. This figure illustrates the definite four-peaked pattern observed at each position.

In an attempt to correlate the sonic pattern with the flow pattern, similar tests were made on sections of the unmachined rod rolled at FMPC, which had the position of the vertical axis in the final pass marked. A 


\section{$\frac{\text { CONFIDENTIAL }}{44}$}

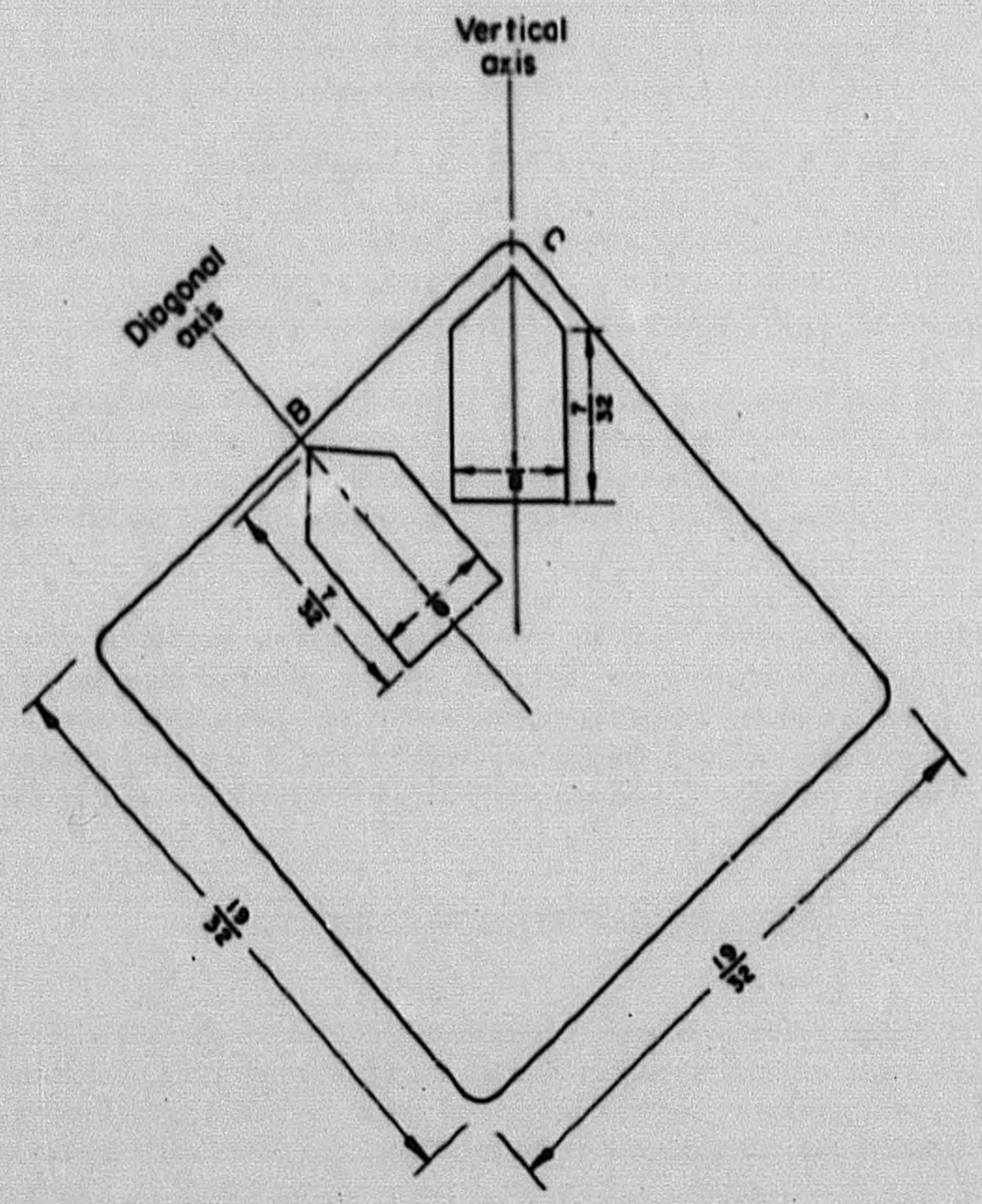

FIGURE 25. LOCATION OF SPECIMENS CUT FROM DIAMOND-ROLLED ROD FOR DILATION TESTS 
CONFIDENTIAL

45

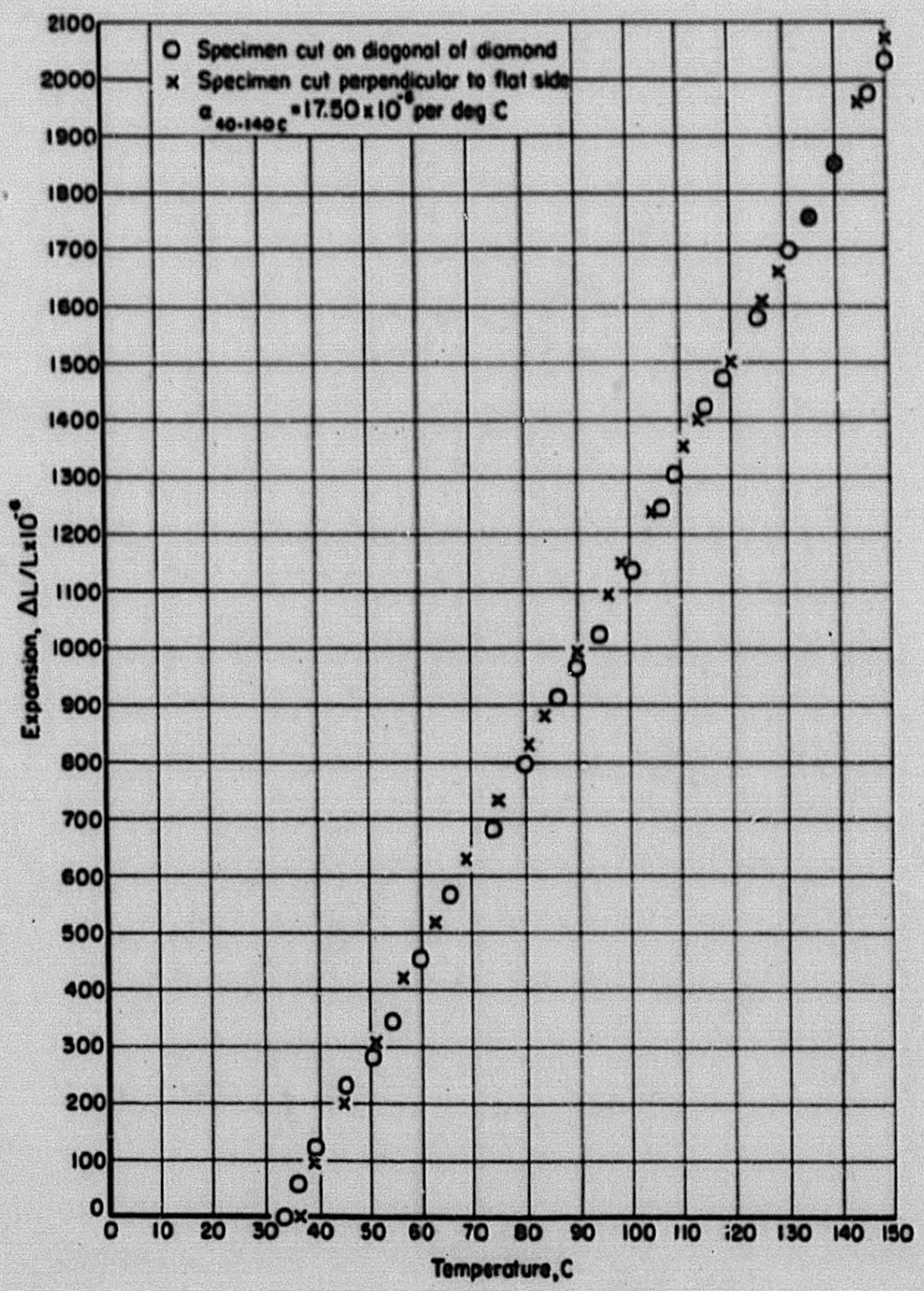

FIGURE 26. LOCAL THERMAL EXPANSION OF ROLLED URANIUM RODS 


\section{CONFIDENTIAL \\ 46}

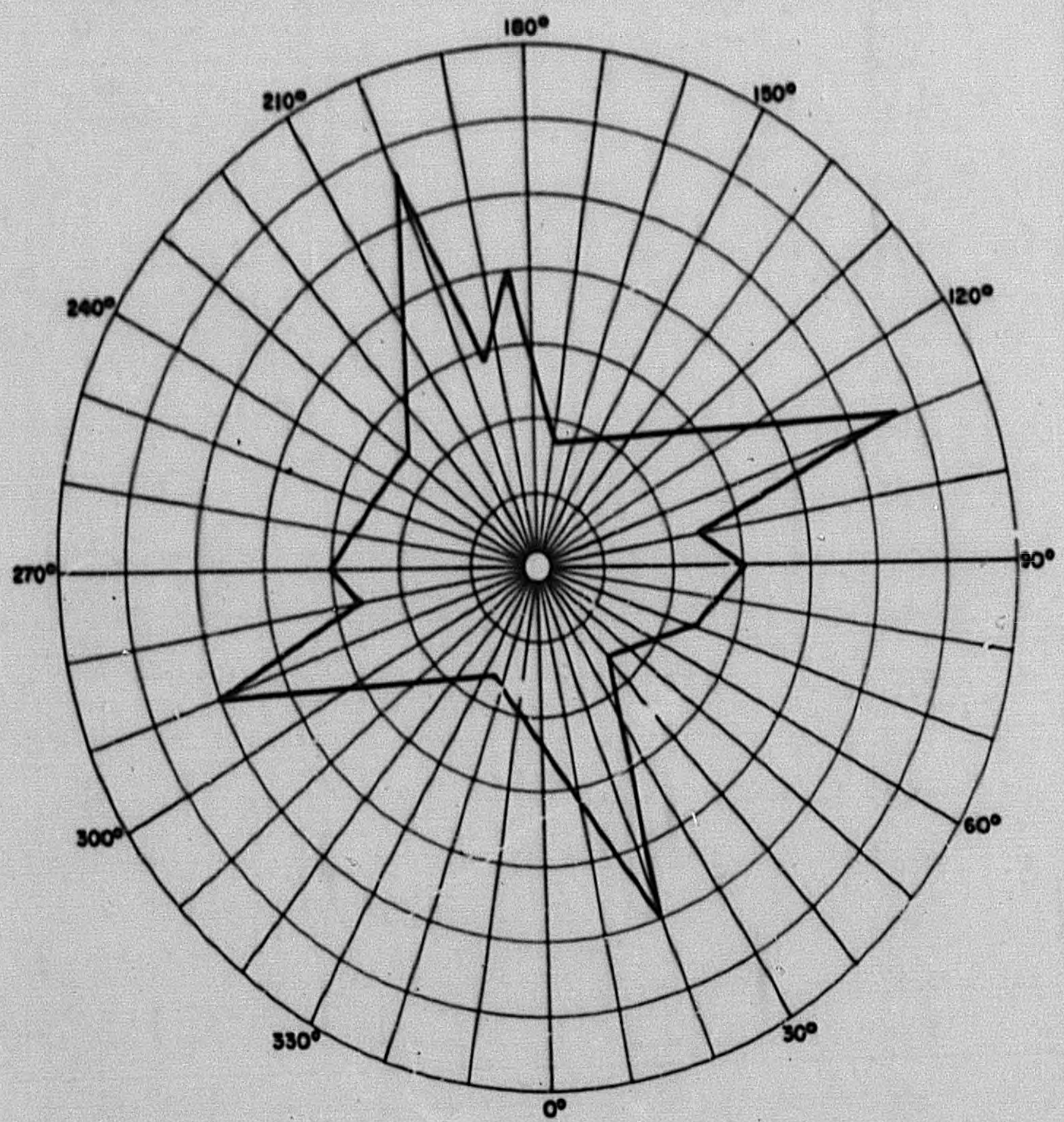

FIGURE 27. RADIAL SONIC-TRANSMISSION PATTERN OF A MACHINED FMPC SWS 


\section{CONFEENTLAL}

nonuniform pattern was observed at each of three points along the length of this rod, as shown in Figure 28. It appears from this pattern that the peaks of transmission occur at approximately 45 deg to the vertical axis.

A similar test run on a section of the same rod after beta heat treatment produced an almost completely uniform pattern around the entire 360 deg (Figure 29).

Although the data are limited, both X-ray diffraction and Plasticine Now patterns indicate that the direction of flow in the FMPC finishing grooives is primarily parallel to the major axis of the oval. Flow at the roll surface is restricted by roll friction and by the shape of the roll. The peaks in the sonic-transmission characteristics thus may be associated with areas of minimum flow or, conversely, the minima may be related to a lowering of the transmission characteristics along the vertical and horizontal axes where maximum lateral flow occurred.

\section{CONCLUSIONS}

Preliminary ptudies of the deformation of Plasticine and uranium in similar grooved rolls indicated that the clay could be used as a stand-in for uranium metal. The radial flow patterns in variously shaped rolls were determined with Plasticine billets made up of colored lamina. The deformation in the FMPC roughing rolls, FMPC finishing rolls, and in diamond and hand-rounding rolls was studied.

Nonuniform radial deformation was observed in rolling a round billet in either the FMPC breakdown rolls or in diamond grooves. The reduction of a square or shaped billet in the FMPC roughing rolls resulted in essentially the same flow pattern as was obtained with a round billet. A square billet reduced in diamond grooves, on the other hand, resulted in a uniform radial flow pattern.

In the FMPC finishing rolls, which have a series of alternate oval and round 8 rooves, the principal deformation occurred along the major axis of the oval. Flow at the surface of the rod adjacent to the rolls was restricted by the shape of the groove and by friction with the roll. In a finished rod rolled in these rolls from a round billet, the deformation appeared to have been quite uniform over the entire cross-sectional area of the rod.

In hand-rounding grooves, the radial deformation of an initially round billet was quite uniform throughout the entire series of reductions. An initially square billet, resulting from the breakdown of a round in diamond grooves, was deformed in such a manner as to equalize the nonuniform radial deformation produced during the breakdown. 

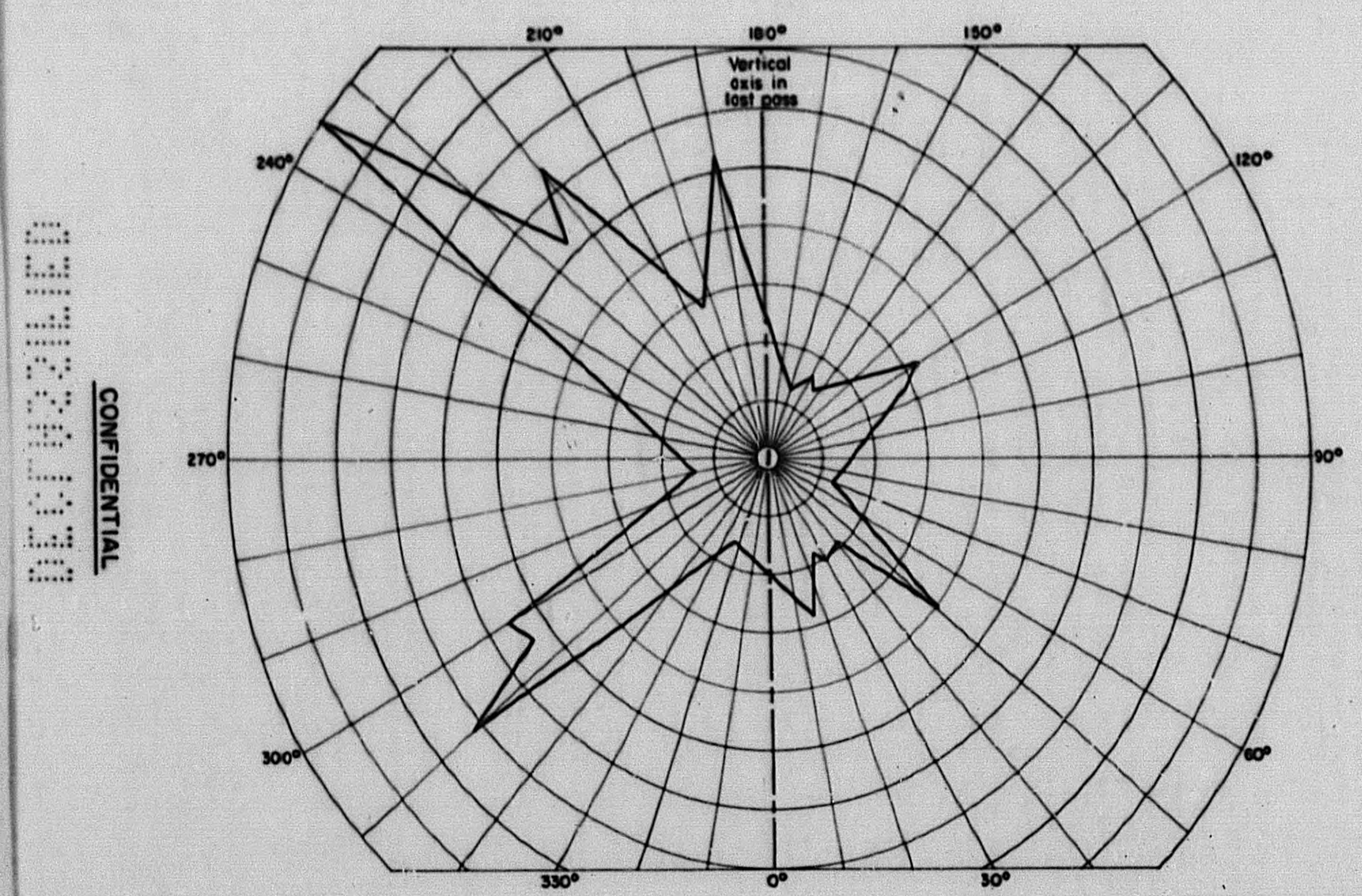

FIGURE 28. RADIAL SONIC-TRANSMISSION PATTERN OF AS-ROLLED UNMACHINED FMPC ROUND ROD 


\section{CONFIDENTIAL}

49

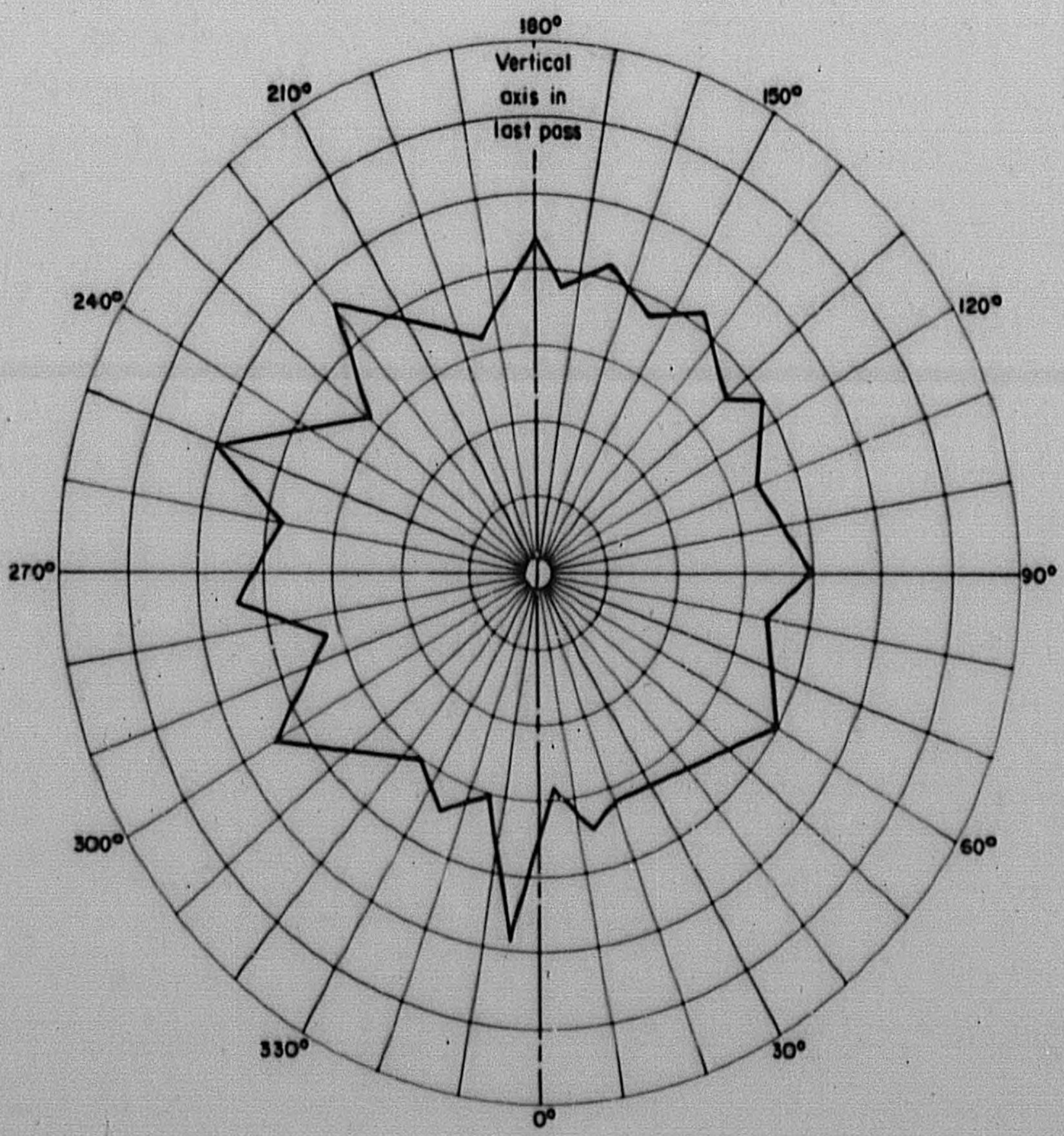

FIGURE 29. RADIAL SONIC-TRANSMISSION PATTERN OF UNMACHINED BETA-TREATED FMPC ROUND ROD 


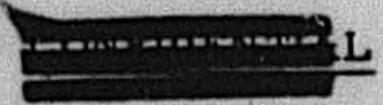

50

X-ray diffraction studies on uranium rod alpha rolled in the FMPC breakdown and finishing rolls and on a round billet rolled in diamond grooves indicated a tendency for the (002) planes to align parallel to the direction of radial flow near the surface of the bar. At the center of the bar, no correlation of pole concentration with the direction of flow was observed.

Ultrasonic-transmission characteristics of an as-rolled FMPC rod showed the typical maxima on two diameters at right angles to each other. These maxima occurred at approximately $45 \mathrm{deg}$ to the vertical axis of the rod in the final groove. The data available indicate a correlation of these maxima with the areas showing the least amount of lateral flow and the lowest degree of preferred orientation.

\section{REFERENCES}

(1) Cook, P. M., Metal Treatment and Drop Forging (November, 1953).

(2) Redding, R., J. Inst. Metals, 26, 246 (1921).

(3) Rosenhain, W., and Tritton, F., J. Inst. Metals, 26, 248 (1921).

(4) Greaves, R., J. Inst. Metals, 26, 254 (1921).

(5) Harris, G. B., Phil. Mag., 43, 113 (1952).

(6) Mueller, M. H., Knott, H. W., Beck, P. A., ANL-5194 (May 1954).

(7) Merrit:, G. E., Bur. Standards J. Research, 10, 59 (1933).

HAS:JRK:LJC/mm 